\title{
Feeding increasing amounts of ruminally protected choline decreased fatty liver in nonlactating, pregnant Holstein cows in negative energy status
}

\author{
M. G. Zenobi, ${ }^{*}$ T. L. Scheffler, ${ }^{*}$ J. E. Zuniga, ${ }^{* 1}$ M. B. Poindexter, ${ }^{*}$ S. R. Campagna, $\dagger$ H. F. Castro Gonzalez, $\dagger$ \\ A. T. Farmer,† B. A. Barton, $\ddagger$ J. E. P. Santos, ${ }^{*}$ and C. R. Staples ${ }^{\star 2}$ \\ *Department of Animal Sciences, University of Florida, Gainesville 32611 \\ †Department of Chemistry, University of Tennessee, Knoxville 37996 \\ ¥Balchem Corp., New Hampton, NY 10958
}

\section{ABSTRACT}

The objectives were to determine the optimal feeding amount of choline in a ruminally protected form to reduce the triacylglycerol (TAG) concentration in liver and to increase TAG in blood plasma of dairy cows. Pregnant, nonlactating multiparous Holstein cows $(\mathrm{n}=$ 77) were blocked by body condition score $(3.59 \pm 0.33)$ and assigned to treatment at $64 \pm 10 \mathrm{~d}$ before calculated calving date. Dietary treatments were top-dressing of $0,30,60,90$, or $120 \mathrm{~g} / \mathrm{d}$ of ruminally protected choline (RPC; Balchem Corp., New Hampton, NY) ions to supply the equivalent of $0,6.5,12.9,19.4$, and 25.8 $\mathrm{g} / \mathrm{d}$ of choline ions. Diets were formulated to exceed nutrient requirements for maintenance and pregnancy and fed in ad libitum amounts for the first $5 \mathrm{~d}$. From d 6 to 15 , cows were restricted to consume approximately $31 \%$ of their net energy requirements to simulate early lactating cows in negative energy balance. Methionine intake was maintained throughout each 15 -d period. Liver was biopsied at 5 and $14 \mathrm{~d}$ and analyzed for TAG and glycogen. Blood was sampled on d 5 and 14 and plasma analyzed for glucose, insulin, cholesterol, $\beta$-hydroxybutyrate, long-chain fatty acids, and haptoglobin. On d 14, a mixture of saturated long-chain fatty acids, ground corn, and dried molasses (50:37:13) was offered (908 g, as-is basis) $10 \mathrm{~h}$ after the single daily feeding. Blood samples were collected for $19 \mathrm{~h}$ and plasma analyzed for TAG and cholesterol to assess apparent absorption of dietary fat. Mean dry matter intake and energy balance decreased from means of 9.5 to $3.3 \mathrm{~kg} / \mathrm{d}$ and from 0.6 to $-9.2 \mathrm{Mcal}$ of net energy for lactation/d during the ad libitum and restricted feeding periods, respectively. Plasma concentrations of the lipid-soluble choline biomolecules, namely total phos-

Received October 10, 2017.

Accepted March 1, 2018.

${ }^{1}$ Current address: San Isidro, Perez Zeledón, San José, Costa Rica.

${ }^{2}$ Corresponding author: chasstap@ufl.edu phatidylcholines, total lysophosphatidylcholines, and sphingomyelin, increased with choline supplementation. Feed restriction increased plasma concentrations of $\beta$-hydroxybutyrate and free long-chain fatty acids, whereas those of glucose, insulin, and total cholesterol decreased. During feed restriction, concentration of hepatic TAG and plasma haptoglobin decreased linearly, whereas concentration of hepatic glycogen tended to increase quadratically with increasing intake of RPC. After fat supplementation, mean plasma concentration of TAG increased by an average of $21 \%$ with intake of RPC ions, peaking at intakes of $\geq 6.5 \mathrm{~g} / \mathrm{d}$ of RPC ion. In summary, feeding RPC ions to cows in negative energy balance had increasing lipotropic effects on the liver when consumed up to $25.8 \mathrm{~g} / \mathrm{d}$, whereas feeding only $6.5 \mathrm{~g} / \mathrm{d}$ increased concentrations of hepatic glycogen and TAG in the blood.

Key words: choline, fatty liver, triacylglycerol

\section{INTRODUCTION}

Usually the liver accumulates triacylglycerol (TAG) during the periparturient period in dairy cows (Bobe et al., 2004) as energy balance (EB) becomes negative. High concentrations of circulating long-chain fatty acids from mobilized TAG from adipose tissue are the precursors for the accumulation of TAG in the liver. Extensive re-esterification of long-chain fatty acids in hepatocytes and the low rates of export of TAG as a key structural component of very low density lipoproteins (VLDL) have been suggested as the cause for development of fatty liver (Grummer, 1993). Ruminant liver has an inherently very low capability of secreting VLDL (Kleppe et al., 1988).

Choline, a micronutrient often classified with the B-vitamins, is a proven lipotropic agent in several species of animals. The daily adequate intake of choline established for adult humans was based on the amount of choline consumed to prevent liver dysfunction (Jiang et al., 2014). Steatosis was observed within 1 wk of withdrawing choline from the diet of rats, but the 
combination of choline and methionine deficiency was more damaging to the liver (Vetelainen et al., 2007). The quantification of VLDL as a limiting transporting molecule to reduce TAG accumulation in cows is lacking. However, treating primary hepatocytes from neonatal Holstein calves with increasing concentrations of choline chloride $(0,61,128,2,028$, and $4,528 \mu \mathrm{mol} / \mathrm{L})$ increased the secretion of VLDL in the medium (Chandler and White, 2017). The supplementation of ruminally protected choline (RPC) ions to periparturient dairy cows (from approximately $21 \mathrm{~d}$ before calving through at least $21 \mathrm{~d}$ postpartum) decreased the postpartum concentration of hepatic TAG in some (Santos and Lima, 2009; Zom et al., 2011; Elek et al., 2013) but not in other experiments (Zahra et al., 2006; Zhou et al., 2016b; Zenobi et al., 2018). The source (ReaShure, Balchem Corp., New Hampton, NY) and amount of RPC ions fed (approximately $12.9 \mathrm{~g} / \mathrm{d}$ ) were the same across these studies with the exception of Elek et al. (2013) who fed $18.6 \mathrm{~g} / \mathrm{d}$ prepartum and $37.3 \mathrm{~g} / \mathrm{d}$ postpartum of RPC ions from a different commercial source (Norcol-25, Nordos, Bussolengo, Italy). Only Piepenbrink and Overton (2003) fed multiple amounts of RPC ions in the same study. They reported that hepatic concentration of TAG decreased numerically on 1 and 21 DIM with increasing intake of RPC ions $(0,9.7,12.9$, and $16.1 \mathrm{~g} / \mathrm{d}$ ) but the trend was not significant (linear effect, $P=0.18$ ). However, the in vitro conversion of carbon-14 palmitate to esterified products in biopsied liver tissue tended to decrease $(P=0.06)$ linearly by $18 \%$ with increasing intake of RPC ions. In addition, the hepatic concentration of glycogen increased linearly with increasing intake of RPC ions.

Supplemental choline may improve the performance of lactating dairy cows through additional mechanisms such as improved intestinal function. The intestinal brush border membrane in rats is composed of equal proportions of phosphatidylcholine (PC) and its precursor, phosphatidylethanolamine (PE), totaling $64 \%$ of the phospholipids (Christon et al., 1991). In addition, $\mathrm{PC}$ is an integral part of the chylomicron molecule, which contains 20\% phospholipid (Hartmann and Lascelles, 1966) of which $100 \%$ was PC (Jenkins et al., 1988) in bovine. Chylomicrons are critical to the movement of lipids and fat-soluble vitamins from the small intestine to the lymphatic vessels for transfer to the blood (Bauchart, 1993). Rats fed a choline-deficient diet and given corn oil by gavage accumulated lipid droplets within the absorptive cells of the small intestine and had a decreased proportion of lipoproteins as chylomicrons in intestinal lymph compared with rats fed a choline-adequate diet. This was corrected when rats received PC by gavage (Takahashi et al., 1982a). Secretion of chylomicrons was impaired and intestinal villi were shorter when lactating rats were fed a diet deficient in choline (da Silva et al., 2015). Intestinal integrity and plasma concentration of TAG was improved when a choline deficiency was corrected in lactating rats (da Silva et al., 2015). The protective barrier of the small intestine in transition dairy cows deteriorated with decreased feed intake and was accompanied by a linear increase in plasma concentration of haptoglobin (Kvidera et al., 2017). Supplemental RPC ions may have beneficial effects during this time period.

The objectives of the current study were to determine the optimal feeding amount of RPC ions to reduce the concentration of TAG in liver and to increase the concentration of TAG in blood of pregnant multiparous Holstein cows in a negative energy state. Based on the recommended adequate intake of choline for a pregnant woman of $450 \mathrm{mg} / \mathrm{d}$ (Jiang et al., 2014) and the ruminal escape of RPC (ReaShure) of $86.1 \%$ (Elek and Husvéth, 2007), our hypothesis was that supplementing 12.9 to $19.4 \mathrm{~g} / \mathrm{d}$ of choline ions to pregnant multiparous Holstein cows in negative EB would optimize concentrations of hepatic and plasma TAG. This animal model was chosen over lactating dairy cows to minimize the variation in EB that exists among newly lactating dairy cows compared with nonlactating dairy cows and still use an animal model that responds to supplemental RPC ions (Cooke et al., 2007). The liver of nonlactating and lactating dairy cows responded similarly to feed restriction (Reid et al., 1979).

\section{MATERIALS AND METHODS}

\section{Cows}

The experiment was conducted at the University of Florida dairy farm from December 2015 to June 2016. Mean and range of daily temperatures were $17.4^{\circ} \mathrm{C}$ and 2.0 to $28.7^{\circ} \mathrm{C}$ and those of daily relative humidity were $75.1 \%$ and 46 to $97 \%$, respectively. All procedures involving cows in the experiment were carried out according to the University of Florida's Institutional Animal Care and Use Committee. Seventy-seven pregnant, nonlactating multiparous Holstein cows were enrolled in the experiment at $64 \pm 10 \mathrm{~d}$ (average $\pm \mathrm{SD}$; range of 41 to $88 \mathrm{~d}$ ) before the calculated calving date. The mean \pm standard deviation and range at enrollment were $3.59 \pm 0.33$ and 2.75 to 4.25 for BCS and $732 \pm$ $96 \mathrm{~kg}$ and 530 to $944 \mathrm{~kg}$ for BW, respectively. Mean number and range of lactations was 1.9 and 1 to 5 . Cows were dried off at the beginning of the experiment and moved to indoor tiestalls each containing an individual air-pressure mattress lightly covered with sand and supplied with individual water bowls and cooled with fans. 


\section{Experimental Design, Treatments, Feeding, and Sample Collection}

The experiment followed a randomized complete block design. Cows ( $\mathrm{n}=5$ to 10$)$ were blocked based on BCS and, within each block, assigned randomly to 1 of 5 treatments. Dietary treatments were top-dressing of 0,30,60, 90, and $120 \mathrm{~g} / \mathrm{d}$ of a RPC product (ReaShure, Balchem Corp.) containing choline chloride to supply $0,6.5,12.9,19.4$, and $25.8 \mathrm{~g} / \mathrm{d}$ of choline ions $(21.5 \%$ choline ions in RPC product). Approximately $86.1 \%$ of consumed RPC ions (ReaShure) would be delivered to the abomasum based on ruminal rate of digestion values obtained using rumen-cannulated ewes (Elek and Husvéth, 2007). If apparent bioavailability of RPC ions in the current study is similar to the $7.8 \%$ reported by de Veth et al. (2016), intake of bioavailable RPC ions was $0,0.5,1.0,1.5$, and $2.0 \mathrm{~g} / \mathrm{d}$ for the 5 treatments. Each experimental period of $15 \mathrm{~d}$ was divided into the following 3 periods: ad libitum (AL) feeding, restricted (R) feeding, and fat loading.

Ad Libitum Period, d 1 to 5 . The first $5 \mathrm{~d}$ of the 15-d experimental period were used to adapt cows from a lactating to a nonlactating diet and to a new housing environment. Cows were offered a TMR (Table 1) formulated to meet or slightly exceed the nutrient requirements of pregnant, nonlactating cows (NRC, 2001) when fed in AL amounts. Diets were offered once daily at $0900 \mathrm{~h}$ and orts were measured immediately before each feeding. The targeted amount of RPC for each treatment was mixed with $75 \mathrm{~g}$ of ground corn, $25 \mathrm{~g}$ of dried molasses, and $14 \mathrm{~g}$ of salt (DM basis) and top-dressed daily to each cow. Cows were weighed and BCS was assessed before feeding on $\mathrm{d} 1$ and 5 . Body condition was scored by 2 individuals using a 1 to 5 scale (Ferguson et al., 1994) with increments of 0.25 units as depicted in the Elanco BCS chart (Elanco Animal Health, 2009). Body weights were averaged and used to calculate the net energy requirement for maintenance and pregnancy. A blood sample was collected by puncture of the coccygeal vessels using evacuated tubes (Vacutainer, Becton Dickinson, Franklin Lakes, NJ) before feeding on d 5 and placed on ice. Liver tissue (0.5 to $1.5 \mathrm{~g}$ wet weight) was collected at d 5 (after $1200 \mathrm{~h}$ ) using a stainless steel percutaneous liver biopsy tool (Aries Surgical, Davis, CA). Areas between the 11th and 13th rib were scanned by ultrasound (Aloka SSD-500V equipped with a $3.5-\mathrm{MHz}$ convex transducer, Aloka Co. Ltd., Tokyo, Japan) to determine the optimal intercostal location for sampling of liver tissue. After rinsing with sterile saline, liver tissue was sliced into 3 sections, transferred into 3 cryovials, snap-frozen in liquid $\mathrm{N}$, and stored at $-80^{\circ} \mathrm{C}$ until analysis for TAG and glycogen concentrations in triplicate.
Restricted Period, d 6 to 14. Cows were offered diets formulated to meet $32 \%$ of the energy and protein required for pregnancy and maintenance (NRC, 2001). This strategy was used to create a negative energy state and force cows to mobilize adipose tissue and increase storage of TAG by the liver. This animal model of feed restriction created fatty liver in nonlactating cows previously (Bertics and Grummer, 1999; Cooke et al., 2007). To achieve the goal of feeding each cow at $32 \%$ of her energy requirement, each cow's $\mathrm{NE}_{\mathrm{L}}$ requirement

Table 1. Ingredient and chemical composition of TMR fed to pregnant, nonlactating Holstein cows during the ad libitum and restricted feeding periods

\begin{tabular}{|c|c|c|}
\hline \multirow[b]{2}{*}{ Item } & \multicolumn{2}{|c|}{ Diet } \\
\hline & Ad libitum & Restricted \\
\hline \multicolumn{3}{|l|}{ Ingredient, $\%$ of DM } \\
\hline Corn silage & 33.7 & 38.4 \\
\hline Triticale silage & 20.1 & 22.9 \\
\hline Bermudagrass hay & 6.67 & 7.52 \\
\hline Wheat straw, chopped & 13.6 & 15.5 \\
\hline Citrus pulp & 7.60 & - \\
\hline Soybean meal & 12.9 & - \\
\hline Mineral-vitamin premix ${ }^{1}$ & 4.20 & 11.2 \\
\hline Corn grain & 0.81 & 2.27 \\
\hline Molasses & 0.27 & 0.76 \\
\hline Salt & 0.15 & 0.60 \\
\hline Smartamine $^{2}$ & - & 0.85 \\
\hline \multicolumn{3}{|l|}{ Chemical composition } \\
\hline $\mathrm{CP}, \%$ of DM & 14.8 & 10.1 \\
\hline $\mathrm{ADF}, \%$ of $\mathrm{DM}$ & 28.5 & 34.0 \\
\hline $\mathrm{NDF}, \%$ of DM & 42.9 & 51.6 \\
\hline Starch, \% of DM & 12.5 & 16.2 \\
\hline Fat, $\%$ of DM & 2.72 & 2.95 \\
\hline $\mathrm{NE}_{\mathrm{L}},{ }^{3} \mathrm{Mcal} / \mathrm{kg}$ of $\mathrm{DM}$ & 1.47 & 1.22 \\
\hline $\mathrm{Ca}, \%$ of $\mathrm{DM}$ & 0.64 & 0.71 \\
\hline $\mathrm{P}, \%$ of DM & 0.32 & 0.31 \\
\hline $\mathrm{Mg}, \%$ of $\mathrm{DM}$ & 0.43 & 0.77 \\
\hline $\mathrm{K}, \%$ of $\mathrm{DM}$ & 1.50 & 1.35 \\
\hline $\mathrm{S}, \%$ of $\mathrm{DM}$ & 0.26 & 0.38 \\
\hline $\mathrm{Na}, \%$ of $\mathrm{DM}$ & 0.13 & 0.38 \\
\hline $\mathrm{Cl}, \% \%$ of $\mathrm{DM}$ & 0.54 & 0.95 \\
\hline Metabolizable methionine, ${ }^{4} \mathrm{~g} / \mathrm{d}$ & 18.7 & 21.9 \\
\hline
\end{tabular}

${ }^{1}$ Contained (DM basis) $62.7 \%$ corn gluten feed, $15.7 \%$ magnesium sulfate $\times 7 \mathrm{H}_{2} \mathrm{O}, 8.9 \%$ calcium carbonate, $6.7 \%$ magnesium oxide, $2.2 \%$ sodium chloride, $2.0 \%$ ClariFly Livestock Premix $0.67 \%$ (Central Garden \& Pet Co, Schaumburg, IL), 0.67\% vitamin E 500,000 kIU/ kg, 0.45\% Sel-Plex 2000 (Alltech Biotechnology, Nicholasville, KY), $0.38 \%$ Rumensin 90 (Elanco Animal Health, Greenfield, IN), $0.27 \%$ IntelliBond Vital 4 (Micronutrients USA LLC, Indianapolis, IN), $0.036 \%$ vitamin A concentrate $650,000 \mathrm{kIU} / \mathrm{kg}, 0.013 \%$ vitamin $\mathrm{D}$ concentrate $500,000 \mathrm{kIU} / \mathrm{kg}$, and $0.002 \%$ ethylenediamine dihydroiodide $80 \%$. Each kilogram contained $13.5 \%$ CP, $3.7 \%$ Ca, $0.9 \%$ P, $5.5 \% \mathrm{Mg}$, $0.9 \% \mathrm{~K}, 2.3 \% \mathrm{~S}, 1.0 \% \mathrm{Na}, 1.6 \% \mathrm{Cl}, 151 \mathrm{mg}$ of Fe, $724 \mathrm{mg}$ of Zn, 165 $\mathrm{mg}$ of $\mathrm{Cu}, 543 \mathrm{mg}$ of $\mathrm{Mn}, 9 \mathrm{mg}$ of Se, $4 \mathrm{mg}$ of Co, $16 \mathrm{mg}$ of I, $233 \mathrm{kIU}$ of vitamin A, $67 \mathrm{kIU}$ of vitamin D, 3,362 IU of vitamin E, $748 \mathrm{mg}$ of monensin, and $139 \mathrm{mg}$ of diflubenzuron.

${ }^{2}$ Smartamine M, Adisseo NA (Alpharetta, GA).

${ }^{3}$ Calculated using chemical composition of analyzed feeds by NRC (2001) software.

${ }^{4}$ Estimated using Cornell-Penn-Miner Institute software (http:// research.vet.upenn.edu/biomath/CurrentProjects/CPMDairy/tabid/1620/Default.aspx). 
(Mcal/d) for maintenance $\left(\mathrm{NE}_{\mathrm{M}}\right)$ and net energy of pregnancy $\left(\mathbf{N E}_{\mathbf{p}}\right)$ was calculated using NRC (2001) equations as follows:

$$
\begin{gathered}
\mathrm{NE}_{\mathrm{M}}=\mathrm{BW}^{0.75} \times 0.073, \text { and } \\
\mathrm{NE}_{\mathrm{p}}=\{[(0.00318 \times \text { day of gestation at enrollment }) \\
-0.03520] \times(\text { calf BW at birth } / 45)\} / 0.218,
\end{gathered}
$$

assuming a calf BW at birth of $40.5 \mathrm{~kg}$ for each cow. The amount of feed DM offered each cow during the $\mathrm{R}$ phase $=\left(\mathrm{NE}_{\mathrm{L}}\right.$ required in Mcal $/ \mathrm{d}$ for maintenance and pregnancy $\times 0.32) \div \mathrm{NE}_{\mathrm{L}}$ density of the TMR (Mcal of $\mathrm{NE}_{\mathrm{L}} / \mathrm{kg}$ of feed $\left.\mathrm{DM}\right)$.

The energy balance during the $\mathrm{AL}$ and $\mathrm{R}$ periods was calculated for each cow using equations from NRC (2001) as the following:

$$
\mathrm{EB}(\mathrm{Mcal} / \mathrm{d})=\mathrm{NE}_{\mathrm{L}} \text { intake }-\mathrm{NE}_{\mathrm{M}}-\mathrm{NE}_{\mathrm{p}} \text {. }
$$

The $\mathrm{NE}_{\mathrm{L}}$ intake $=\mathrm{DMI}(\mathrm{kg} / \mathrm{d}) \times \mathrm{NE}_{\mathrm{L}}$ density of TMR (Mcal/kg of dietary DM). Actual EB at the time of enrollment was recalculated after each cow delivered her calf so that actual BW of her newborn calf could be used in the equations.

The RPC was mixed with ground corn $(75 \mathrm{~g})$, dried molasses (25 g), salt (20 g), and a rumen-protected methionine product $(28 \mathrm{~g})$ containing $70 \%$ DL-methionine (Smartamine M, Adisseo NA, Alpharetta, GA; DM basis) and top-dressed daily to each cow. The methionine product added $15.7 \mathrm{~g}$ of metabolizable methionine per cow per day (NRC, 2001) to provide the same amount of metabolizable methionine in the $\mathrm{R}$ period as consumed during the AL period, using the actual chemical composition of the experimental diet and assuming a DMI of $12 \mathrm{~kg} / \mathrm{d}$. Both methionine and choline serve as methyl donors metabolically. Six percent of circulating choline was derived from $28 \%$ of radioactive-labeled methionine but radioactive-labeled choline did not contribute to circulating methionine in lactating goats (Emmanuel and Kennelly, 1984). By providing the same amount of dietary methionine in both the $\mathrm{AL}$ and $\mathrm{R}$ periods, the role of dietary choline could be isolated. The mineralvitamin premix comprised a greater proportion of the TMR during this period compared with the AL period to meet micronutrient requirements (Table 1 ).

Cows were weighed and BCS was assessed before feeding on d 14. To check for hyperketonemia, whole blood was collected just prior to feeding from coccygeal vessels on d 5,10,12, and 14 and tested for concentration of BHB immediately using a Precision Xtra meter (Abbott Laboratories, Abbott Park, IL), a handheld device with a fairly high sensitivity and specificity when compared with serum BHB concentrations determined spectrophotometrically (Iwersen et al., 2009). A blood sample and liver tissue (0.5 to $1.5 \mathrm{~g}$ wet weight) were collected at d 14 and processed as described previously.

Fat Loading Period, d 14 to 15. A SFA supplement (454 g; Energy Booster Mag, Milk Specialties, Carpentersville, IL) was mixed with $340 \mathrm{~g}$ of finely ground corn and $114 \mathrm{~g}$ of dried molasses (as-is basis) and fed on d 14 at $1900 \mathrm{~h}$. Blood was sampled using evacuated tubes containing $\mathrm{K}_{2}$ EDTA as the anticoagulant (Vacutainer, Becton Dickinson) at 0, 5, 7, 9, 11, $13,15,17$, and $19 \mathrm{~h}$ relative to the time of fat loading and processed for plasma as previously described. This approach was used to assess the effect of diet on uptake of long-chain fatty acids by the small intestine of rats (da Silva et al., 2015). Three cows (consuming 0, 12.9, or $25.8 \mathrm{~g}$ of RPC ions) were excluded from the analyses because they did not consume the fat supplement.

General Sample Collections and Processing. Feeds were sampled every $3 \mathrm{~d}$, dried at $55^{\circ} \mathrm{C}$ for 72 $\mathrm{h}$ in a forced-air oven, and dry weight was recorded. The DMI of individual cows was calculated based on $\mathrm{DM}$ of individual feeds measured at $105^{\circ} \mathrm{C}$. The forageto-concentrate ratios of the TMR were adjusted every $3 \mathrm{~d}$ if necessary. Dried individual feed samples were ground to pass a 4-mm screen of a Wiley mill (Thomas Scientific, Swedesboro, NJ). Samples were composited monthly and analyzed using wet chemistry procedures (Dairyland Laboratories Inc., Arcadia, WI). The energy density of the TMR was calculated (NRC, 2001) using chemical analysis of dietary ingredients and actual DMI.

Blood was sampled $4 \mathrm{~h}$ after feeding, with $\mathrm{K}_{2}$ EDTA used as an anticoagulant, during the AL and R feeding periods for analysis of choline, its biomolecules, and their fatty acyl chain moieties. Within $30 \mathrm{~min}$ of collection, blood samples were centrifuged at $1,125 \times g$ for 15 min, plasma was harvested, and multiple aliquots of $1.5 \mathrm{~mL}$ were frozen at $-80^{\circ} \mathrm{C}$ until analysis. Plasma isolated using sodium heparin as an anticoagulant was analyzed for glucose, total cholesterol, insulin, TAG, long-chain fatty acids, and BHB. Bertics and Grummer (1999) reported that sampling blood just before feeding resulted in numerically greater values for glucose, BHB, and long-chain fatty acids compared with sampling $4 \mathrm{~h}$ after feeding.

\section{Sample Analyses}

All chemical analyses included a common control sample to calculate inter-assay variation. A Technicon Autoanalyzer (Technicon Instruments Corp., Chauncey, NY) was used to measure concentrations of plasma glucose (Bran and Luebbe Industrial Method 339-19; 
Gochman and Schmitz, 1972) in duplicate. Inter- and intraassay coefficients of variation $(\mathbf{C V})$ were 7.0 and $5.9 \%$, respectively. Concentrations of long-chain fatty acids (NEFA-C kit, Wako Diagnostics Inc., Richmond, VA; as modified by Johnson and Peters, 1993) and BHB (Wako Autokit 3-HB, Wako Diagnostics Inc.) were determined using enzyme assays in duplicate. Intra- and interassay CV were 1.5 and $6.9 \%$ and 1.7 and $4.9 \%$ for long-chain fatty acids and BHB, respectively. Concentrations of insulin were analyzed using an ELISA kit (Mercodia Bovine Insulin ELISA, Mercodia Inc., Uppsala, Sweden). Intra- and interassay CV were 10.1 and $9.8 \%$, respectively. For concentrations of total cholesterol (Cholesterol E kit, Wako Diagnostics Inc.) and TAG (Stanbio Triglycerides LiquiColor Procedure No. 2100, Stanbio Laboratory, Boerne, TX), samples were analyzed in triplicate. Intra- and interassay CV were 3.5 and $5.3 \%$ for cholesterol and 1.3 and $2.2 \%$ for TAG, respectively. Just before feeding the fat supplement (time 0), plasma haptoglobin was determined by measuring the differences in $\mathrm{H}_{2} \mathrm{O}_{2}$ activity with haptoglobin-hemoglobin as described by Makimura and Suzuki (1982) and reported as optical density $\times$ 100. Intra- and interassay CV were 7.6 and $15.6 \%$ for haptoglobin, respectively.

Isotope dilution mass spectrometry was used to quantify choline and choline biomolecules in plasma. The internal standard (IS) stock solutions were prepared in methanol. The following standards were used for this analysis: choline chloride-trimethyl-d9 (Cho-d9, Cambridge Isotope Laboratories, DLM 549-1, Tewksbury, MA), betaine-d11 (Bet-d11, Cambridge Isotope Laboratories, DLM 407), phosphorylcholine chloridetrimethyl-d9 (PCho-d9, Cambridge Isotope Laboratories, DLM-298), 18:0 PC-d9 (PC-d9, Avanti Polar Lipids, 860362, Alabaster, AL), 16:0-d31 sphingomyelin (SM-d31, Avanti Polar Lipids, 868584), acetylcholined13 bromide (ACho-d13, C/D/N Isotopes, ICN D-1780, Quebec, Canada), lysophosphatidylcholine-methyl-d3 (LPC-d3, Larodan, 71-2826, Malmo, Sweden). The concentrations of choline biomolecules were calculated using the ratio between the area of the target compound and the area of the IS multiplied by the known IS concentration and corrected for dilution factors. Plasma samples were extracted based on the method described by Artegoitia et al. (2014). The samples were kept on ice throughout the extraction process. The extraction solvent was stored at $-20^{\circ} \mathrm{C}$ and consisted of chloroform, methanol, and water (1:2:0.8). Briefly, $1 \mathrm{~mL}$ of extraction solvent was added to $200 \mu \mathrm{L}$ of plasma and $40 \mu \mathrm{L}$ of the IS solution. The samples were centrifuged at $28,620 \times g$ and $4^{\circ} \mathrm{C}$ for $5 \mathrm{~min}$. The resultant supernatant was transferred into a separate glass vial. The extraction procedure was repeated and the supernatant collected into the same vial. The combined extracts were dried under a constant nitrogen steam and then re-suspended in $3 \mathrm{~mL}$ of methanol. Three hundred microliters of the re-suspended extracts was transferred to an autosampler vial for analysis. Choline biomolecules were analyzed by hydrophilic interaction ultraperformance liquid chromatography UPLC-MS methods adapted from Artegoitia et al. (2014). An Ultimate 3000 pump and autosampler (Thermo Fisher Scientific, Waltham, MA) were used to introduce the samples onto an Accucore HILIC column $(150 \times 2.1$ mm, $2.6 \mu \mathrm{m}$ particles, Thermo Fisher Scientific) for UPLC separation. The autosampler tray temperature was set to $4^{\circ} \mathrm{C}$ and partial loop injections of $10 \mu \mathrm{L}$ were used. The column temperature was set to $30^{\circ} \mathrm{C}$ and a $0.2 \mathrm{~mL} / \mathrm{min}$ flow rate was used. The mobile phases were $10 \mathrm{~m} M$ ammonium formate in water buffered to $\mathrm{pH} 3.0$ with formic acid (solvent A) and acetonitrile (solvent B). A 30-min gradient was performed: Time $(\mathrm{t})=0.0 \mathrm{~min}, 8 \%$ solvent $\mathrm{A} ; \mathrm{t}=0.1 \mathrm{~min}, 8 \%$ solvent $\mathrm{A} ; \mathrm{t}=10.0 \mathrm{~min}, 30 \%$ solvent $\mathrm{A} ; \mathrm{t}=15.0 \mathrm{~min}, 70 \%$ solvent $\mathrm{A} ; \mathrm{t}=18.0 \mathrm{~min}, 70 \%$ solvent $\mathrm{A} ; \mathrm{t}=18.01 \mathrm{~min}$, $8 \%$ solvent $\mathrm{A} ; \mathrm{t}=30.0 \mathrm{~min}, 8 \%$ solvent $\mathrm{A}$. The scan range was 100 to $850 \mathrm{~m} / z$ with a resolution of 140,000 . An electrospray ionization source was used in positive mode for the analysis. The ion source parameters were $4.5 \mathrm{kV}$ electrospray ionization voltage and $290^{\circ} \mathrm{C}$ capillary temperature. Nitrogen was used as a sheath gas set to 40 arbitrary units. Data were processed using MAVEN (Melamud et al., 2010).

Samples of liver were thawed on ice, blotted dry, and approximately $0.1 \mathrm{~g}$ of tissue was homogenized in 1 $\mathrm{mL}$ of saline in triplicate using an ultra-Turrax T25 homogenizer (Rose Scientific Ltd., Edmonton, AB, Canada). After addition of $1 \mathrm{~mL}$ of saline and $1 \mathrm{~mL}$ of methanol, samples were split into 3 aliquots. Dry matter was determined from $0.5 \mathrm{~mL}$ of homogenized liver sample by drying for $48 \mathrm{~h}$ in a $55^{\circ} \mathrm{C}$ forced-air oven and correcting for DM contributed by saline. The second aliquot $(2 \mathrm{~mL})$ was analyzed for TAG (Folch et al., 1957) using a colorimetric assay (Foster and Dunn, 1973). The third aliquot was used to measure DNA content of the sample (Labarca and Paigen, 1980). Intraassay variation for TAG was $4.1 \%$ (DM basis) and $2.0 \%$ (DNA basis).

For glycogen analysis, $50 \mathrm{mg}$ of frozen liver tissue in duplicate was ground to a powder in liquid $\mathrm{N}$ using a mortar and pestle and then diluted with 10 volumes (wt/vol) of $2 \mathrm{M} \mathrm{HCl}$ based on the procedure of Passonneau and Lauderdale (1974). Samples were homogenized with a Precellys 24 Homogenizer (Bertin Instruments, Hialeah, FL) at 5,000 rpm for three 10-s intervals using zirconia beads $(2.0 \mathrm{~mm}$, catalog no. 11079124zx, BioSpec Products, Bartlesville, OK). 
Homogenates were heated at $95^{\circ} \mathrm{C}$ for $2 \mathrm{~h}$ and frequently vortexed to convert glycogen into glucose units. Samples were then centrifuged at $10,000 \times g$ for 10 min at $4^{\circ} \mathrm{C}$ and supernatant transferred to a new tube. Supernatants were neutralized 1:1 (vol/vol) with $2 M$ $\mathrm{NaOH}$. Glucose concentration was determined using an enzyme analytical method (Bergmeyer, 1974) adapted to a 96-well plate assay (Hammelman et al., 2003). For glucose analysis, the reaction buffer contained 100 $\mathrm{m} M$ triethanolamine, $6.8 \mathrm{~m} M$ EDTA ( $\mathrm{pH}$ 7.6), $9.8 \mathrm{~m} M$ $\mathrm{MgCl}_{2}, 0.5 \mathrm{~m} M \mathrm{NADP}$, and $1.2 \mathrm{~m} M$ ATP. The reaction was initiated by the addition of 1 unit of hexokinase and glucose-6-phosphate dehydrogenase per well. Glycogen concentration (glucose equivalents) was detected by the change in absorbance at $340 \mathrm{~nm}$ used to measure the conversion of NADP to NADPH. Glucose concentration was determined from standards of increasing glucose concentrations. Intraassay variation was $4.5 \%$.

\section{Statistical Analyses}

The experiment was a randomized, complete block design. Nine blocks of cows were enrolled. Cow was the experimental unit and considered random. Data collected during the AL, R, and fat-loading phases of each experimental period were analyzed separately using the MIXED procedure of SAS version 9.4 (SAS/STAT, SAS Institute Inc., Cary, NC). For data collected at single time points only (i.e., BW, BCS, DMI, EB, liver composition, and concentration of plasma metabolites in the AL and $\mathrm{R}$ feeding periods), the MIXED procedure of SAS was used and the model included the fixed effects of treatment and the random effect of block. For dependent variables measured over time during the fatloading period, the REPEATED statement was used and the model included the fixed effects of treatment, time, and interaction between treatment and time; block was included as a random effect. The random effect of cow nested within treatment was the error term for testing the effects of treatment. When an interaction with time was significant, treatment means at time points of measure were partitioned using the SLICE command of SAS. The $\mathrm{AR}(1)$ and $\mathrm{SP}(\mathrm{POW})$ covariance structures were tested and the one with the lowest Akaike's information criterion was selected for each dependent variable. The Kenward-Roger method was used to calculate the denominator degrees of freedom for the $F$ tests. Four single degree of freedom contrasts were tested that included linear, quadratic, and cubic effects of RPC ions as well as the contrast of 0 RPC ion versus all other RPC ion treatment amounts combined. Actual BW of calves and number of days between enrollment and calving were used as covariates if $P \leq$ 0.30 for the covariates because those factors influence energy requirements and thus EB. Continuous data were tested for the distribution of the residuals using Shapiro-Wilk and homogeneity of variance by plotting residuals against predicted values. Nonnormally distributed data were subjected to Box-Cox transformation using the TRANSREG procedure of SAS to achieve normality before statistical analysis. The least squares means were back-transformed and standard errors of the mean were calculated as outlined by Jørgensen and Pedersen (1998). Pearson correlation coefficients between dependent variables were calculated using PROC CORR of SAS. Statistical significance was declared at $P \leq 0.05$ and a tendency was considered at $0.05<P$ $\leq 0.10$. The BHB values in plasma provided by use of the Precision Xtra meter were not statistically analyzed because BHB values were determined more accurately using enzymatic analysis as described previously.

\section{RESULTS}

\section{Ad Libitum Feeding Period}

One cow, fed $12.9 \mathrm{~g} / \mathrm{d}$ of RPC ions, was removed from the experiment on $\mathrm{d} 8$ of the experimental period because she was not adjusting to her new tiestall housing as evidenced by very low DMI during the AL phase, high BHB, and eventual treatment for clinical ketosis. No other cow was treated for ketosis. Intake of DM averaged $9.5 \mathrm{~kg} / \mathrm{d}$ instead of the assumed intake of 12 $\mathrm{kg} / \mathrm{d}$. As a result, the intake of metabolizable methionine was $18.7 \mathrm{~g} / \mathrm{d}$ (Table 1). During the AL feeding period, mean BW (732 kg) and BCS (3.59) did not differ among treatments (Table 2). Cows consuming 12.9 or $19.4 \mathrm{~g} / \mathrm{d}$ of RPC ions tended to consume approximately $0.5 \mathrm{~kg} / \mathrm{d}$ more DM (quadratic effect, $P=$ 0.07 ) and were in a slightly more positive EB (quadratic effect, $P=0.05)$ compared with the other treatment groups (Table 2). As expected, plasma concentrations of long-chain fatty acids and BHB were low (Table 3), reflecting cows in positive $\mathrm{EB}$ when fed $\mathrm{AL}$ amounts of feed. Concentration of long-chain fatty acids in plasma decreased from 298 to $227 \mu \mathrm{Eq}$ as intake of RPC ions increased from 0 to $12.9 \mathrm{~g} / \mathrm{d}$ before increasing to 323 $\mu \mathrm{Eq}$ in cows fed $25.8 \mathrm{~g}$ of RPC ions (quadratic effect, $P=0.01$; Table 3). Concentration of BHB followed the same pattern as that of long-chain fatty acids to increasing intake of RPC ions, but the quadratic effect was not significant $(P=0.24)$. Plasma concentration of glucose responded in the opposite way compared with long-chain fatty acids and BHB concentrations, with glucose concentrations peaking when cows were fed $6.5 \mathrm{~g}$ of RPC ions and decreasing in cows fed more RPC ions, but again the pattern was not significant (quadratic effect; $P=0.13$ ). Plasma concentrations of 
Table 2. Effect of increasing intake of ruminally protected choline (RPC) ions on BW, BCS, DMI, and energy status during the ad libitum and restricted feeding periods of pregnant, nonlactating multiparous Holstein cows

\begin{tabular}{|c|c|c|c|c|c|c|c|c|c|c|}
\hline \multirow[b]{2}{*}{ Measures } & \multicolumn{5}{|c|}{$\begin{array}{c}\text { Treatment } \\
\text { ( } \mathrm{g} \text { of choline ions supplemented daily) }\end{array}$} & \multirow[b]{2}{*}{ SEM } & \multicolumn{4}{|c|}{$P$-value ${ }^{1}$} \\
\hline & 0 & 6.5 & 12.9 & 19.4 & 25.8 & & Linear & Quad & Cubic & 0 vs. rest \\
\hline \multicolumn{11}{|l|}{ Ad libitum feed intake } \\
\hline $\mathrm{BW}, \mathrm{kg}$ & 746 & 730 & 715 & 720 & 748 & 26 & 0.94 & 0.22 & 0.77 & 0.51 \\
\hline BCS & 3.58 & 3.61 & 3.60 & 3.55 & 3.61 & 0.09 & 0.98 & 0.96 & 0.60 & 0.89 \\
\hline Energy balance, Mcal/d & 0.5 & 0.4 & 1.5 & 1.3 & -0.6 & 0.8 & 0.54 & 0.04 & 0.15 & 0.79 \\
\hline Energy intake, ${ }^{2} \%$ & 105 & 104 & 113 & 111 & 97 & 6 & 0.50 & 0.05 & 0.20 & 0.86 \\
\hline \multicolumn{11}{|l|}{ Restricted feed intake } \\
\hline $\mathrm{BW}, \mathrm{kg}$ & 711 & 695 & 695 & 684 & 716 & 24 & 1.00 & 0.34 & 0.70 & 0.62 \\
\hline BCS & 3.51 & 3.51 & 3.50 & 3.41 & 3.48 & 0.09 & 0.55 & 0.81 & 0.51 & 0.70 \\
\hline DMI, kg & 3.33 & 3.30 & 3.27 & 3.28 & 3.35 & 0.07 & 1.00 & 0.32 & 0.75 & 0.64 \\
\hline DMI, $\%$ of BW & 0.47 & 0.48 & 0.47 & 0.48 & 0.47 & 0.01 & 0.85 & 0.61 & 0.65 & 0.87 \\
\hline
\end{tabular}

${ }^{1}$ Statistical test of linear, quadratic (quad), and cubic effects of treatments as well as $0 \mathrm{~g} / \mathrm{d}$ of RPC vs. $(6.5+12.9+19.4+25.8 \mathrm{~g} / \mathrm{d}$ of RPC).

${ }^{2} \%$ of energy requirements for maintenance and pregnancy (NRC, 2001).

insulin and TAG responded to RPC ion treatments in the same manner with values being greatest in AL-fed cows consuming 6.5 or $25.8 \mathrm{~g} / \mathrm{d}$ of RPC ions (cubic effect, $P \leq 0.03$; Table 3 ). Mean plasma concentrations of total cholesterol and haptoglobin were not affected by treatments.
Hepatic glycogen increased linearly from $24.8 \%$ to approximately $27.5 \%$ (DM basis) with increasing intake of RPC ions $(P=0.02)$ during the period of positive EB (Figure 1). When choline treatments collectively were compared with the control treatment, glycogen concentration increased $(P=0.01)$ by $12.9 \%$. Intake

Table 3. Effect of increasing intake of ruminally protected choline ions on plasma metabolites, insulin, and haptoglobin during the ad libitum (d 5) and restricted (d 9) feeding periods of pregnant, nonlactating multiparous Holstein cows

\begin{tabular}{|c|c|c|c|c|c|c|c|c|c|c|}
\hline \multirow[b]{2}{*}{ Variables } & \multicolumn{5}{|c|}{$\begin{array}{c}\text { Treatment } \\
\text { (g of choline ions supplemented daily) }\end{array}$} & \multirow[b]{2}{*}{ SEM } & \multicolumn{4}{|c|}{$P$-value ${ }^{1}$} \\
\hline & 0 & 6.5 & 12.9 & 19.4 & 25.8 & & Linear & Quad & Cubic & 0 vs. rest \\
\hline \multicolumn{11}{|c|}{ Fatty acids, $\mu M$} \\
\hline Ad libitum & 298 & 241 & 227 & 285 & 323 & 37 & 0.28 & 0.01 & 0.47 & 0.36 \\
\hline Restricted & 1,179 & 1,123 & 1,136 & 1,237 & 1,069 & 111 & 0.67 & 0.64 & 0.20 & 0.69 \\
\hline \multicolumn{11}{|l|}{$\mathrm{BHB}, \mathrm{m} M$} \\
\hline \multicolumn{11}{|c|}{ Glucose, $\mathrm{mg} / \mathrm{dL}$} \\
\hline Ad libitum & 74.8 & 76.7 & 75.6 & 74.7 & 73.8 & 1.1 & 0.18 & 0.13 & 0.36 & 0.74 \\
\hline Restricted & 62.7 & 64.5 & 63.5 & 62.8 & 59.7 & 1.4 & 0.04 & 0.04 & 0.89 & 0.95 \\
\hline \multicolumn{11}{|c|}{ Insulin, $\mathrm{ng} / \mathrm{mL}$} \\
\hline Ad libitum & 0.70 & 0.90 & 0.78 & 0.70 & 0.90 & 0.10 & 0.43 & 0.89 & 0.02 & 0.20 \\
\hline Restricted & 0.09 & 0.12 & 0.11 & 0.10 & 0.14 & 0.03 & 0.26 & 0.74 & 0.25 & 0.34 \\
\hline \multicolumn{11}{|c|}{ Triacylglycerol, mg/dL } \\
\hline \multicolumn{11}{|c|}{ Haptoglobin, $\mathrm{OD} \times 100^{2}$} \\
\hline Ad libitum & 0.46 & 0.40 & 0.36 & 0.54 & 0.41 & 0.03 & 0.88 & 0.65 & 0.14 & 0.61 \\
\hline Restricted & 3.30 & 3.58 & 4.46 & 3.83 & 3.70 & 1.03 & 0.52 & 0.26 & 0.96 & 0.35 \\
\hline
\end{tabular}

${ }^{1}$ Statistical test of linear, quadratic (quad), and cubic effects of treatments as well as $0 \mathrm{~g} / \mathrm{d}$ of RPC vs. $(6.5+12.9+19.4+25.8 \mathrm{~g} / \mathrm{d}$ of RPC). ${ }^{2} \mathrm{OD}=$ optical density. Reverse-transformed means after transformation of original data using inverse square root and square root approaches for ad libitum and restricted periods, respectively, due to nonnormal distribution of the residuals. 


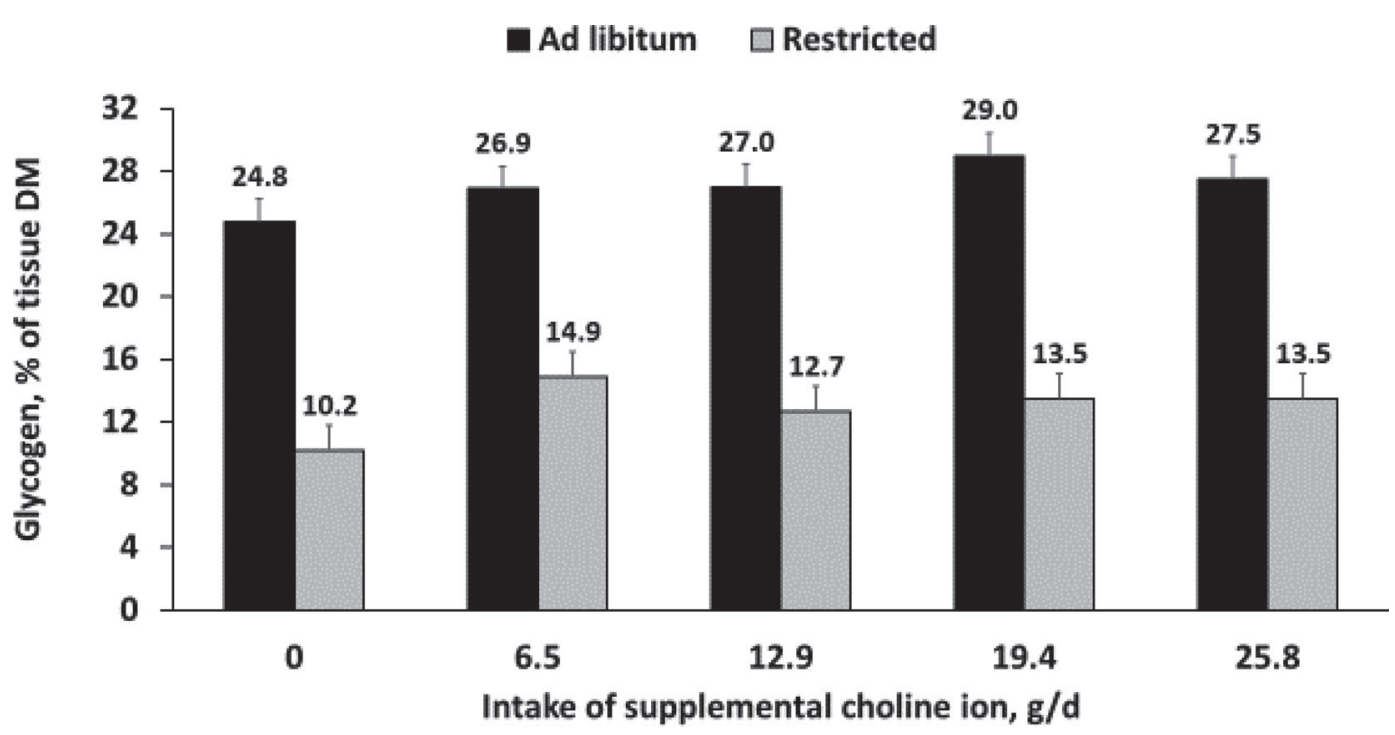

Figure 1. Effect of increasing intake of ruminally protected choline (RPC) ions on hepatic concentration of glycogen during the ad libitum and restricted feeding periods of pregnant, nonlactating multiparous Holstein cows. During ad libitum intake of feed, concentration of hepatic glycogen increased linearly with increasing intake of supplemental choline $(P=0.02)$. During restricted feed intake, concentration of hepatic tissue of cows supplemented with RPC ions $(6.5$ to $25.8 \mathrm{~g} / \mathrm{d})$ had greater mean concentration of glycogen compared with that of cows not fed RPC (13.6 vs. $10.2 \%$; effect of control vs. rest, $P=0.01$ ). Error bars represent SEM. Pooled SEM were 1.44 and 1.63 for ad libitum and restricted feeding, respectively.

of RPC ions did not alter concentrations of liver TAG during AL feeding (Figures $2 \mathrm{~A}$ and $2 \mathrm{~B}$ ) and values were within the expected range ( $2 \%$ of tissue DM) for wellfed nonlactating, pregnant dairy cows (Greenfield et al., 2000). The TAG values expressed as a proportion of DNA were lowest of the 2 methods (expressed on a DM and DNA basis), which agrees with Greenfield et al. (2000). Pearson correlations between the 2 reporting methods were $\mathrm{r}=0.80(P<0.01)$ during $\mathrm{AL}$ feed intake and $\mathrm{r}=0.95(P<0.01)$ during $\mathrm{R}$ feed intake, indicating close agreement between the 2 methods. The $\mathrm{RPC}$ treatments did not affect the hepatic ratio of TAG to glycogen, with a mean of 0.09 (Figure 3 ).

Of all choline biomolecules detected, PC was detected in greatest concentration by far followed by sphingomyelin (SM), betaine, lysophosphatidylcholine (LPC), free choline, and phosphocholine (PCh; Table 4). Concentration of the water-soluble choline biomolecules (choline, betaine, and $\mathrm{PCh}$ ) were unchanged due to treatment but those of the lipid-soluble biomolecules were increased due to RPC ion supplementation. Plasma concentrations of SM increased linearly $(P<0.01)$ and those of total LPC and total choline biomolecules tended to increase linearly $(P \leq 0.10)$ with increasing intake of RPC ions (Table 4). Cows fed RPC ion treatments collectively had greater $(P \leq 0.05)$ circulating concentrations of SM (467 vs. $400 \mu M)$, total PC $(3,931$ vs. $3,152 \mu M)$, total LPC (81.0 vs. $68.5 \mu M)$, and total choline biomolecules (4,516 vs. $3,650 \mu M)$ compared with cows not fed RPC ions (0 vs. rest; Table 4). Of the 4 single fatty acyl chain moieties of LPC, the concentrations of LPC with UFA (C18:1 or C18:2) increased linearly $(P \leq 0.02)$ with increasing intake of RPC ions, whereas LPC with C18:0 tended to increase quadratically $(P=0.09$; Table 5$)$. As a result, cows fed RPC ion treatments collectively had greater $(P \leq$ 0.04) circulating concentrations of all LPC fatty acyl moieties with the exception of LPC containing C16:0 compared with cows not fed RPC ions (0 vs. rest; Table 5). Of the 15 fatty acyl chain moieties of PC detected, the circulating concentrations of $8 \mathrm{PC}$ containing fatty acyl chains of C16:0/C16:0, C16:0/C16:1, C16:0/C20:3, C16:0/C20:5; C16:1/C20:4, C18:0/C181, C18:0/C18:2; $\mathrm{C} 18: 1 / \mathrm{C} 18: 1$, and $\mathrm{C} 18: 0 / \mathrm{C} 20: 3$ increased or tended to increase in a linear or quadratic fashion with increasing intake of RPC ions (Table 5). As a result, cows fed RPC ion treatments collectively had greater or tended to have greater circulating concentrations of $\mathrm{PC}$ with these fatty acyl chain moieties compared with cows not fed RPC ions (0 vs. rest; Table 5).

\section{Restricted Feeding Period}

Intake of DM and metabolizable methionine averaged $3.3 \mathrm{~kg} / \mathrm{d}$ and $21.9 \mathrm{~g} / \mathrm{d}$, respectively (Tables 2 and 1 , respectively). The intake of metabolizable methionine was approximately $3 \mathrm{~g} / \mathrm{d}$ greater than that of cows fed AL due to a slight excess supplementation of 
rumen-protected methionine in anticipation of an $\mathrm{AL}$ DMI of $12 \mathrm{~kg} / \mathrm{d}$. During the conduct of the experiment and before knowledge of the BW of the newborn calf, intake of calories was calculated to be at $32 \%$ of their $\mathrm{NE}_{\mathrm{L}}$ requirement assuming that all calves would weigh $40.5 \mathrm{~kg}$ at birth. Calculated intake of $\mathrm{NE}_{\mathrm{L}}$ during the $\mathrm{R}$ feeding period was corrected by the actual birth weight of the calves and averaged $30.7 \%$ of requirement (Table 2). Mean BW (700 kg), BCS (3.48), DMI (3.31 $\mathrm{kg} / \mathrm{d}$,) and $\mathrm{EB}\left(-9.2 \mathrm{Mcal}\right.$ of $\left.\mathrm{NE}_{\mathrm{L}} / \mathrm{d}\right)$ did not differ among treatments. The $-9.2 \mathrm{Mcal}$ of $\mathrm{NE}_{\mathrm{L}} / \mathrm{d}$ (Table 2) is within the expected range of $\mathrm{EB}$ of lactating dairy cows in the first 2 wk of lactation. On average, cows were $31.6 \mathrm{~kg}$ lighter (700.2 vs. $731.8 \mathrm{~kg}$ ) and 0.1 BCS units less (3.50 vs. 3.60) during the $\mathrm{R}$ compared with the AL feeding period reflecting the drastic decrease in DMI. Restricting DMI increased circulating concentrations of long-chain fatty acids and BHB by 4 -fold and 2.5-fold, respectively, whereas those of glucose, insulin, cholesterol, and TAG were all decreased from as little as $16 \%$ for glucose to as much as $87 \%$ for insulin (Table $3)$. These changes reflect the decreased energy status of the cows caused by the decreased intake of calories, thus creating a metabolic state similar to the lactating dairy cow in the first few weeks postpartum. Mean plasma concentration of haptoglobin was 3.77 optical density $\times 100$, being greater than the concentration during AL feeding, but unaffected by feeding RPC ions.

Increasing intake of RPC ions did not affect $\mathrm{BW}$ or $\mathrm{BCS}$ at the end of the R period (Table 2) nor were
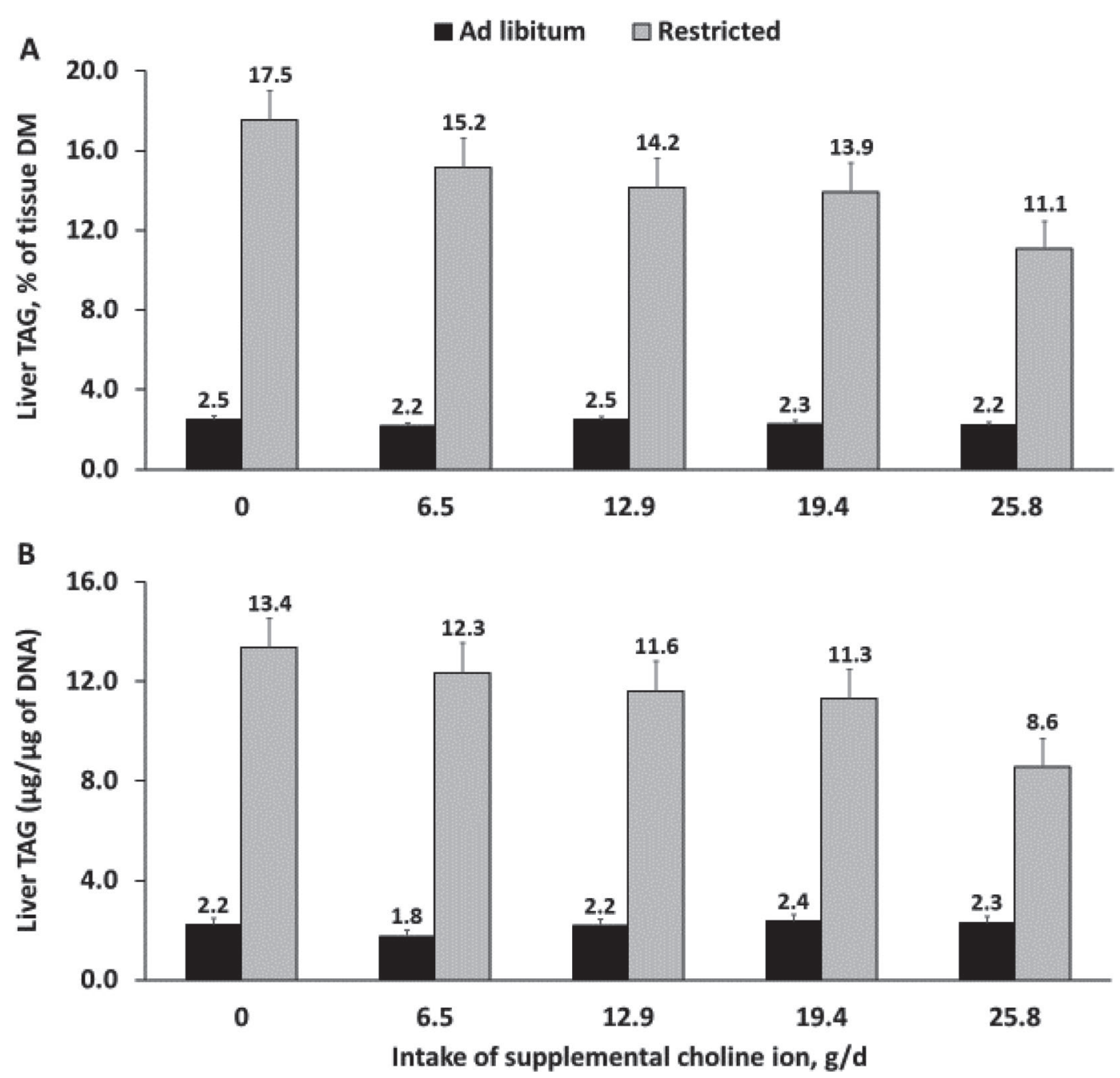

Figure 2. Effect of increasing intake of ruminally protected choline ions on hepatic concentration of triacylglycerol (TAG) expressed as a percentage of liver DM (panel A) and as micrograms per microgram of DNA (panel B) during the ad libitum and restricted feeding periods of pregnant, nonlactating multiparous Holstein cows. (A) Ad libitum feed intake: no effect of choline intake; restricted feed intake: linear decrease with increasing intake of choline ions $(P<0.001)$; 0 vs. all choline ion intakes $(P=0.003)$. (B) Ad libitum feed intake: no effect of choline intake; restricted feed intake: linear decrease with increasing intake of choline ions $(P<0.001)$; 0 vs. all choline ion intakes $(P=0.03)$. Error bars represent SEM. Pooled SEM were 0.26 and 1.18 for ad libitum and restricted feeding, respectively. 


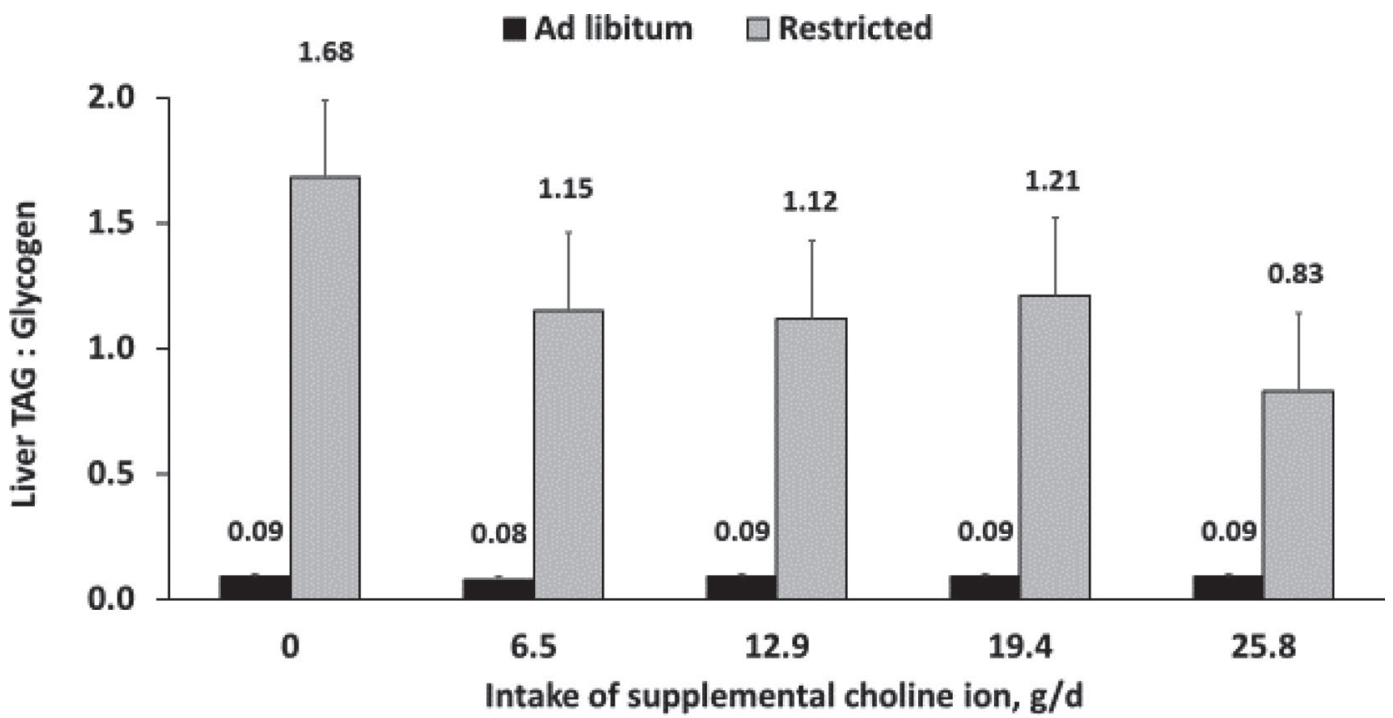

Figure 3. Effect of increasing intake of ruminally protected choline (RPC) ions on hepatic ratio of triacylglycerol (TAG) to glycogen during the ad libitum and restricted feeding periods of pregnant, nonlactating multiparous Holstein cows. Least squares means and SEM were backtransformed after using natural log to transform the data to obtain normal residuals. During ad libitum intake of feed, ratio was unaffected by treatments. During restricted feed intake, ratio decreased linearly with increasing intake of RPC ions $(P=0.01)$. Cows fed $0 \mathrm{~g} / \mathrm{d}$ of $\mathrm{RPC}$ ions had a greater ratio compared with cows fed RPC ions (1.68 vs. 1.08; effect of control vs. rest, $P=0.02)$. Error bars represent SEM. Pooled SEM were 0.01 and 0.31 for ad libitum and restricted feeding, respectively.

circulating concentrations of long-chain fatty acids, BHB, insulin, and TAG affected (Table 3) when these metabolites were measured immediately before feeding. Plasma concentrations of glucose decreased in cows fed
$25.8 \mathrm{~g} / \mathrm{d}$ of RPC ions (quadratic effect, $P=0.04$; Table $3)$. The glucose and the BHB responses (linear increase, $P=0.11$; Table 3 ) to increasing intake of RPC ions were in the opposite direction. This negative relation-

Table 4. Effect of increasing intake of ruminally protected choline (RPC) ions on plasma concentrations of choline and choline-containing biomolecules during the ad libitum (d 5) and restricted (d 9) feeding periods of pregnant, nonlactating multiparous Holstein cows

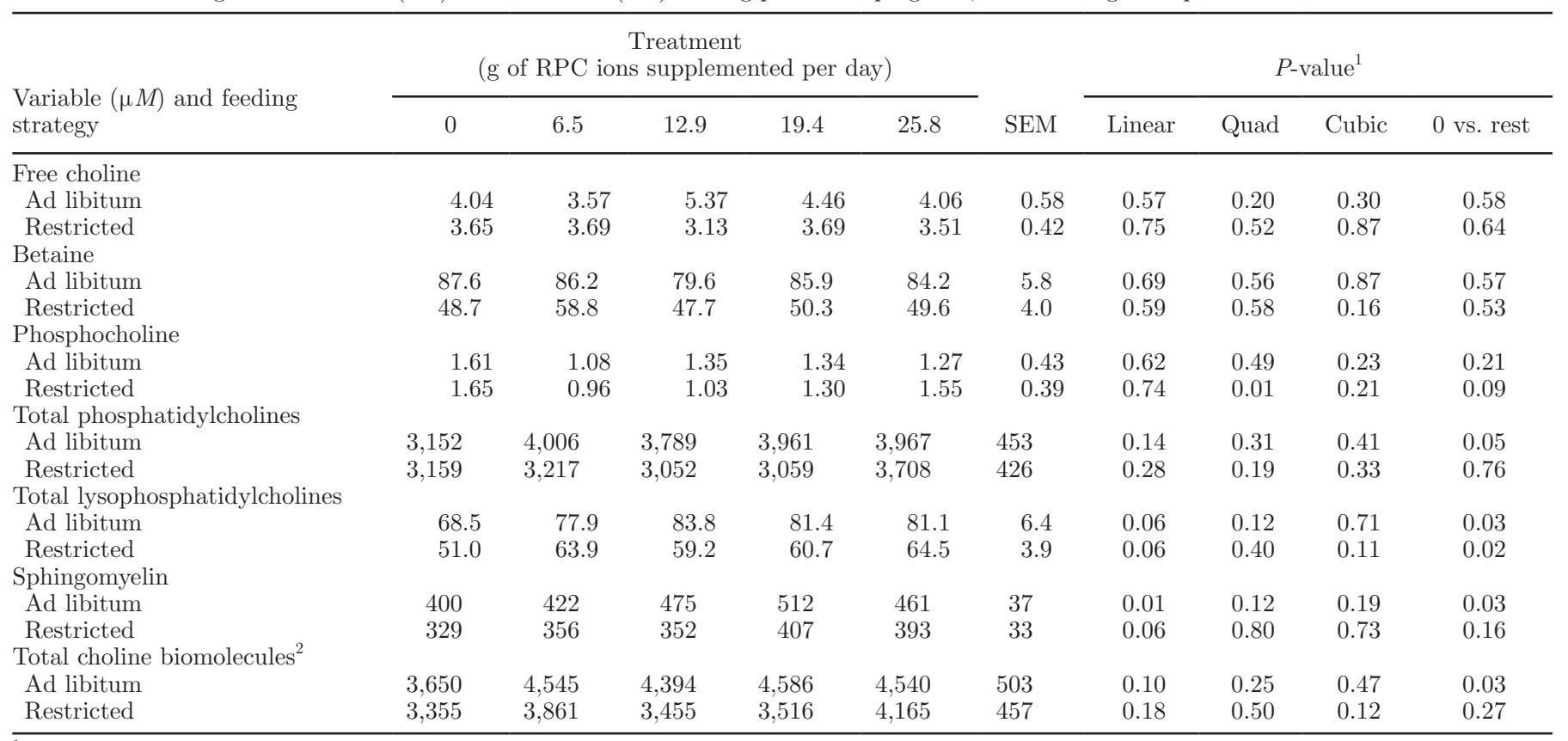

${ }^{1}$ Statistical test of linear, quadratic (quad), and cubic effects of treatments as well as $0 \mathrm{~g} / \mathrm{d}$ of RPC vs. $(6.5+12.9+19.4+25.8 \mathrm{~g} / \mathrm{d}$ of RPC).

${ }^{2}$ Sum of choline, phosphocholine, total phosphatidylcholines, total lysophosphatidylcholines, and sphingomyelin. 
Table 5. Effect of increasing intake of ruminally protected choline (RPC) ions on plasma concentrations of lysophosphatidylcholine and phosphatidylcholine with particular fatty acyl chains during the ad libitum (d 5) and restricted (d 9) feeding periods of pregnant, nonlactating multiparous Holstein cows

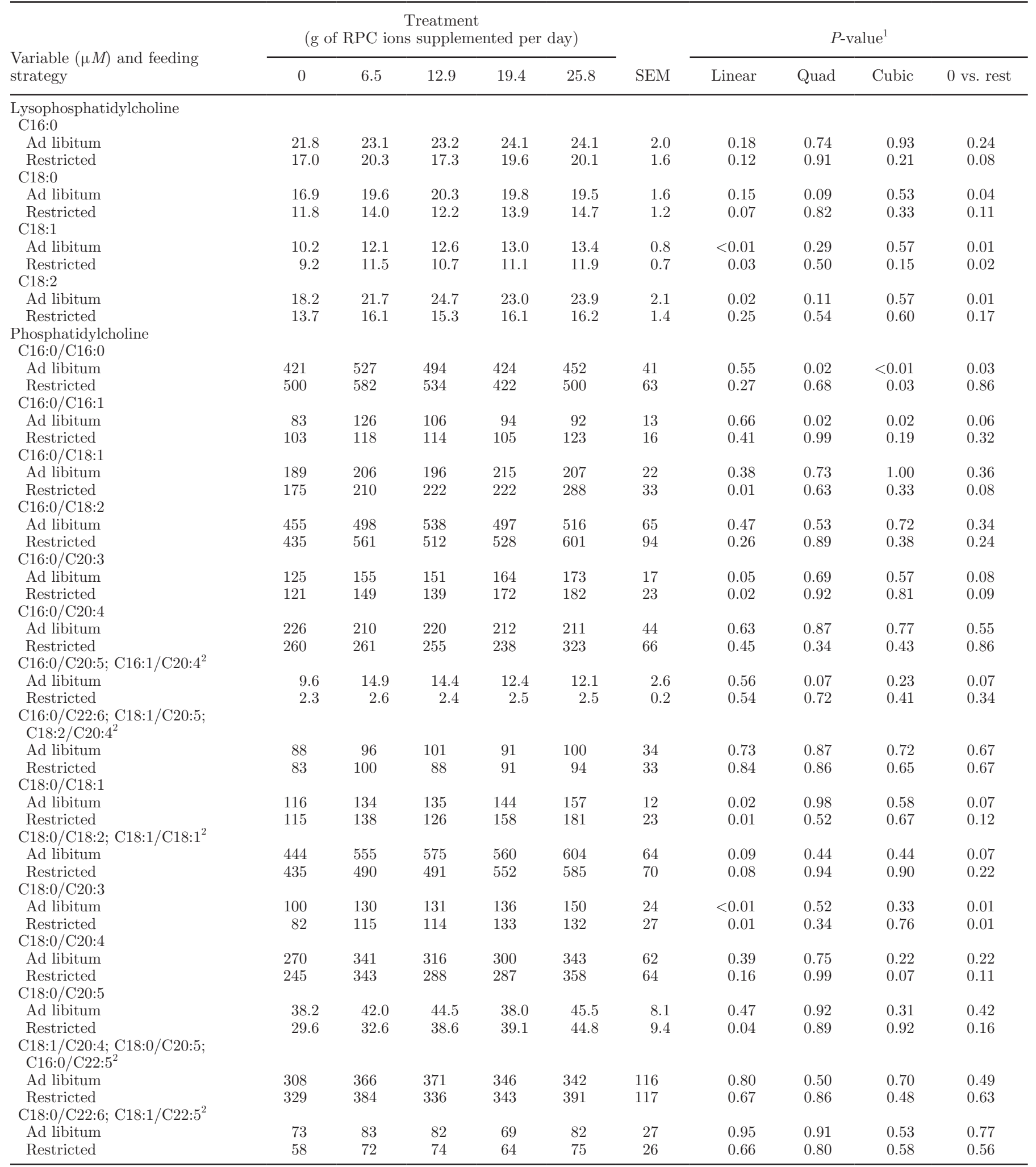

${ }^{1}$ Statistical test of linear, quadratic (quad), and cubic effects of treatments as well as $0 \mathrm{~g} / \mathrm{d}$ of RPC vs. $(6.5+12.9+19.4+25.8 \mathrm{~g} / \mathrm{d}$ of RPC).

${ }^{2}$ Two or three possible combinations of fatty acids were identified by the same product ions using HILIC LC-MS/MS. 
Table 6. Pearson correlation coefficients among concentrations of plasma triacylglycerol (TAG), cholesterol, glucose, insulin, BHB, and longchain fatty acids (FA) and hepatic concentrations of glycogen and TAG from pregnant, nonlactating multiparous Holstein cows fed to $31 \%$ of the energy required for pregnancy and maintenance for $9 \mathrm{~d}$

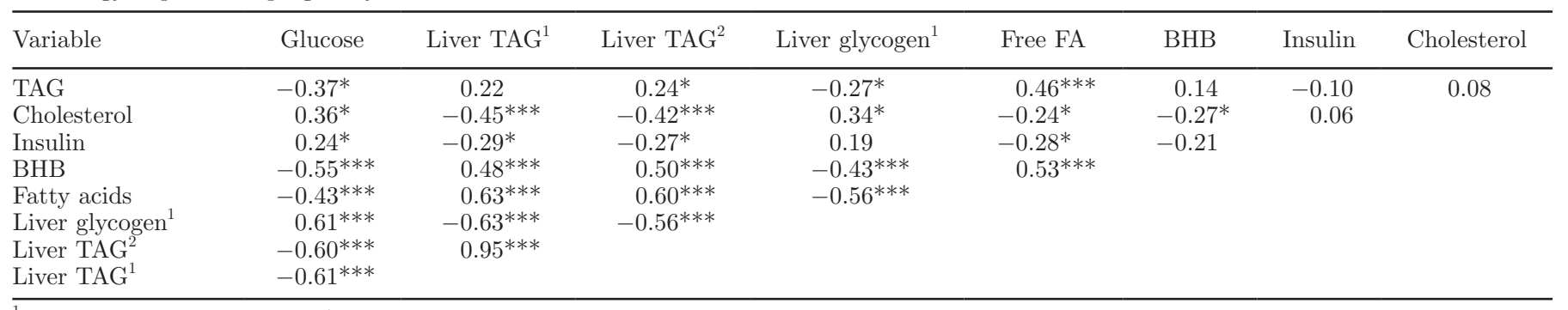

${ }^{1}$ Expressed as a percentage of DM.

${ }^{2}$ Expressed as micrograms of TAG per microgram of DNA.

${ }^{*} P<0.05 ;{ }^{* * *} P \leq 0.001$.

ship between plasma glucose and BHB concentrations was confirmed by a correlation of $-0.55(P<0.001$; Table 6). Plasma concentration of total cholesterol increased linearly $(P=0.05)$ with increasing intake of $\mathrm{RPC}$ ions (Table 3 ).

Restricting DMI to nonlactating, pregnant cows dramatically decreased the hepatic concentration of glycogen by $58 \%$, from $24.8 \%$ during AL to $10.2 \%$ during $\mathrm{R}$ feeding (DM basis; Figure 1). Hepatic tissue of cows supplemented with the 4 amounts of RPC ions (6.5 to $25.8 \mathrm{~g} / \mathrm{d}$ ) had greater mean concentration of glycogen compared with that of cows not fed RPC ions (13.6 vs. $10.2 \%, \mathrm{DM}$ basis; effect of control vs. rest, $P=$ 0.01, Figure 1). Concurrently, R feeding increased the hepatic concentration of TAG 7 -fold, from 2.5 to $17.5 \%$ (DM basis, Figure 2A). Concentration of hepatic TAG during negative $\mathrm{EB}$ was decreased in a linear fashion by increasing intake of RPC when expressed on a DM basis $(P=0.02$; Figure $2 \mathrm{~A})$ and on a DNA basis $(P$ $<0.001$; Figure 2B). The extent of TAG decrease was $37 \%$, decreasing from 17.5 to $11.1 \%$ (DM basis) for cows fed 0 and $25.8 \mathrm{~g} / \mathrm{d}$ of RPC ions, respectively. The extent of TAG decrease when expressed on a DNA basis were similar ( $36 \%$ decrease) to that when expressed on a DM basis, decreasing from 13.4 to $8.6 \mu \mathrm{g} / \mu \mathrm{g}$ of DNA for cows fed 0 and $25.8 \mathrm{~g} / \mathrm{d}$ of RPC ions, respectively. The hepatic ratio of TAG to glycogen decreased linearly with increasing intake of RPC ions $(P=0.01$; Figure 3). The full extent of the decrease reached $50 \%$ (from 1.68 to 0.83 ) largely due to decreasing concentration of hepatic TAG, although both TAG and glycogen concentrations were affected by feeding RPC ions.

Concentration of hepatic TAG (DM basis) was correlated positively with plasma concentrations of BHB (r $=0.48)$ and long-chain fatty acids $(\mathrm{r}=0.63)$ and correlated negatively with concentration of hepatic glycogen $(-0.63)$, plasma insulin $(\mathrm{r}=-0.29)$, and cholesterol ( $\mathrm{r}$ $=-0.45$; Table 6$)$. Concentration of hepatic glycogen was correlated positively with plasma cholesterol $(\mathrm{r}=$ $0.34)$ but negatively with plasma BHB $(\mathrm{r}=-0.43)$ and long-chain fatty acids $(\mathrm{r}=-0.56)$.

Plasma concentrations of LPC and SM tended to increase linearly $(P=0.06)$ with increasing intake of $\mathrm{RPC}$ ions (Table 4). Cows fed RPC ion treatments collectively had greater ( $P=0.02 ; 0$ vs. rest) circulating concentrations of total LPC (62.1 vs. $51.0 \mu M)$ compared with cows not fed RPC ions (Table 4). Circulating concentration of $\mathrm{PCh}$ responded in an opposite fashion to the other choline biomolecules in that it decreased quadratically with increasing intake of RPC ions, with the lowest concentration in cows supplemented with $6.5 \mathrm{~g} / \mathrm{d}$ of RPC ions. Of the 4 single fatty acyl chain moieties of LPC detected, the plasma concentrations of LPC with $\mathrm{C} 18: 1$ increased linearly $(P=0.03)$ and that of LPC with C18:0 tended to increase linearly ( $P$ $=0.07$ ) with increasing intake of RPC ions (Table 5). Analyzing the individual fatty acyl chain moieties of PC (Table 5) can provide insight that analysis for total PC alone may miss. For example, total PC moieties were not affected by RPC supplementation. However, 6 (C16:0/C18:1, C16:0/C20:3, C18:0/C181, C18:0/C18: 2; C18:1/C18:1, C18:0/C20:3, and $\mathrm{C} 18: 0 / \mathrm{C} 20: 5)$ of the 15 fatty acyl chain moieties of PC detected were increased or tended to increase linearly with increasing intake of RPC ions (Table 5). Cows fed RPC ion treatments collectively had greater or tended to have greater circulating concentrations of $3 \mathrm{PC}$-containing fatty acyl chains of $\mathrm{C} 16: 0 / \mathrm{C} 18: 1, \mathrm{C} 16: 0 / \mathrm{C} 20: 3$, and $\mathrm{C} 18: 0 / \mathrm{C} 20$ : 3 compared with cows not fed RPC ions (0 vs. rest; Table 5).

\section{Dietary Fat Loading}

On the day of fat supplementation, pre-prandial concentrations of plasma TAG ranged from 17.0 to 19.3 $\mathrm{mg} / \mathrm{dL}$ for the 5 treatments and was not affected by in- 
take of RPC ions (Table 3; Figure 4A). The mean concentration of plasma TAG across the $19 \mathrm{~h}$ of sampling after fat-loading increased (quadratic effect, $P=0.03$ ) in cows receiving supplemental RPC ions compared with cows fed $0 \mathrm{~g} / \mathrm{d}$, being 13.6, 17.4, 16.9, 16.0, and $15.7 \mathrm{mg} / \mathrm{dL}$ for cows consuming $0,6.5,12.9,19.4$, and $25.8 \mathrm{~g} / \mathrm{d}$ of RPC ions, respectively (Table 7). Compared with $10 \mathrm{~h}$ before fat loading, the mean concentration of plasma TAG (from 0 to $19 \mathrm{~h}$ after fat loading) in cows fed $0 \mathrm{~g} / \mathrm{d}$ of RPC ion dropped 4.3 units to $12.7 \mathrm{mg} /$ $\mathrm{dL}$, whereas cows fed RPC ions averaged across the 4 treatments dropped a mean of 1.6 units to $16.3 \mathrm{mg} / \mathrm{dL}$ $(P<0.10$ at time 0 ; Figure $4 \mathrm{~A})$. Treatment differences also were detected at $13 \mathrm{~h}(P<0.10)$ and 15 and $17 \mathrm{~h}$ $(P<0.05)$ after fat consumption (treatment by time interaction, $P=0.09$ ). Mean concentration of plasma TAG after fat loading was greater in cows fed RPC ion treatments collectively compared with the those fed 0 g/d (16.5 vs. $13.6 \mathrm{mg} / \mathrm{dL} ; 0$ vs. rest, $P=0.01$; Figure $4 \mathrm{~B})$.

Mean concentrations of plasma cholesterol were 115, $116,128,128$, and $126 \mathrm{mg} / \mathrm{dL}$ for cows fed $0,6.5,12.9$,
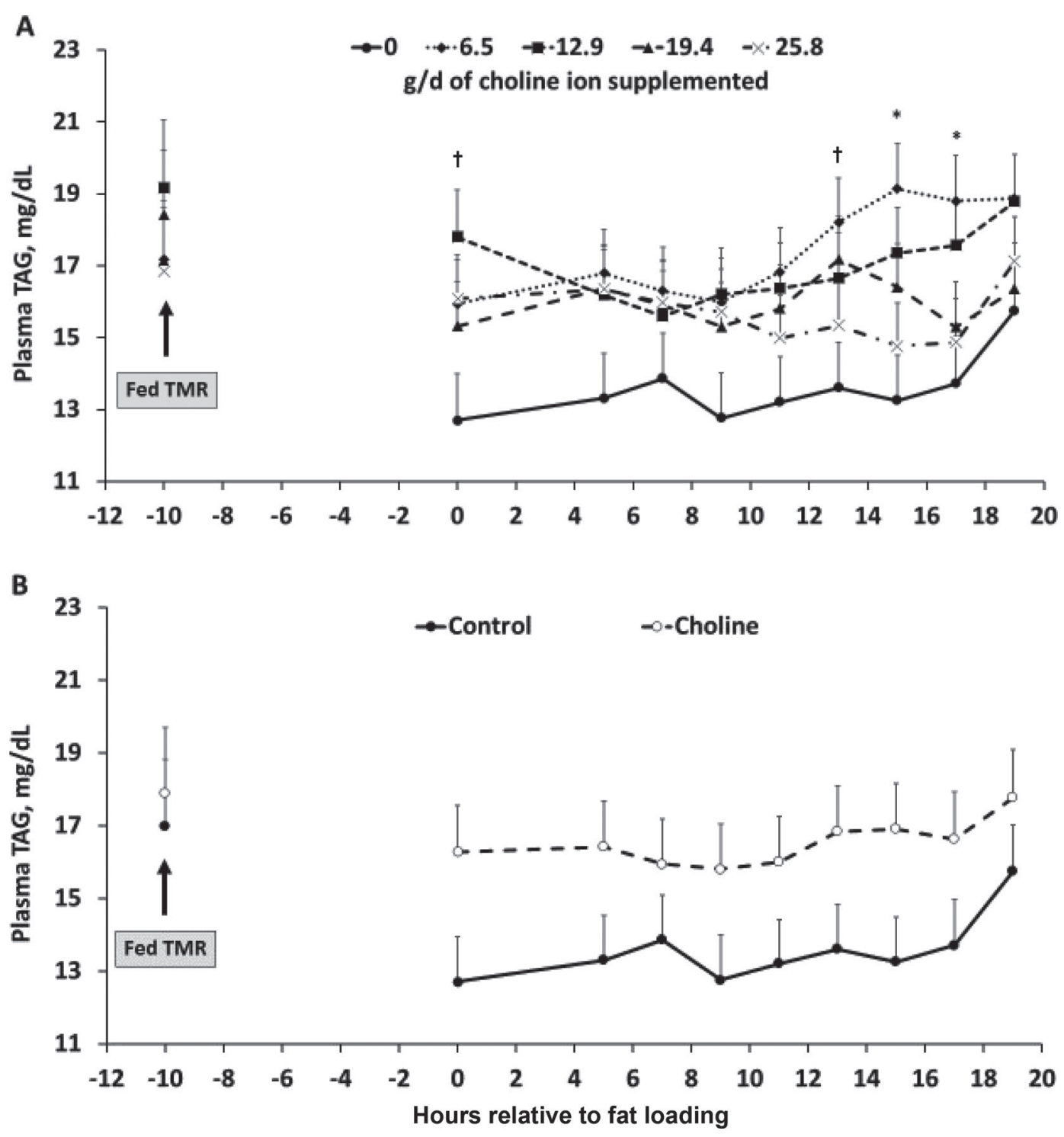

Figure 4. Effect of increasing intake of ruminally protected choline (RPC) ions on plasma concentration of triacylglycerol (TAG) after a pulse feeding of fat for each treatment (A) and for control $(0 \mathrm{~g} / \mathrm{d})$ vs. sum of all choline ion treatments (B) to pregnant, nonlactating multiparous Holstein cows. The mean concentration of plasma TAG across the $19 \mathrm{~h}$ of sampling $(\mathrm{n}=9$ samples) increased quadratically with increasing intake of RPC ions $(P=0.03)$, being 13.6, 17.4, 16.9, 16.0, and $15.7 \mathrm{mg} / \mathrm{dL}$ for cows fed $0,6.5,12.9,19.4$, and $25.8 \mathrm{~g} / \mathrm{d}$ of RPC ions, respectively (A), and was less $(P=0.01)$ for cows fed $0 \mathrm{~g} / \mathrm{d}$ vs. all other RPC ion treatments $(13.6$ vs. $16.5 \mathrm{mg} / \mathrm{dL} ; \mathrm{B})$. Symbols $\dagger$ and $*$ represent $P<0.10$ and $<0.05$, respectively, in panel A. Error bars represent SEM. Pooled SEM was 1.24. 
19.4, and $25.8 \mathrm{~g} / \mathrm{d}$ of RPC ions, respectively (Table 7). Treatment means did not differ although concentrations of plasma cholesterol tended to fluctuate across time differently among treatments after fat supplementation (treatment by time interaction, $P=0.08$, Table 7; Figure 5A and 5B). Differences among treatments were not detected at any hour of measure using the SLICE command option of SAS.

Plasma concentrations of glucose and insulin were not affected by intake of RPC ions but that of haptoglobin decreased linearly $(P=0.03)$ with increasing intake of $\mathrm{RPC}$ ions, being $1.64,0.94,0.72,0.85$, and 0.67 optical density $\times 100$ for cows fed $0,6.5,12.9,19.4$, and 25.8 $\mathrm{g} / \mathrm{d}$ of RPC ions, respectively (Table 7 ).

\section{DISCUSSION}

\section{Plasma Metabolites in AL and R Feeding Phases}

In a meta-analysis of 13 studies using lactating dairy cows, DMI increased by $0.7 \mathrm{~kg} / \mathrm{d}$ when cows consumed, on average, $12.9 \mathrm{~g} / \mathrm{d}$ of RPC ions (Grummer, 2012), which is similar to the increase detected in the current study of $0.5 \mathrm{~kg} / \mathrm{d}$ when cows consumed 12.9 or $19.4 \mathrm{~g} / \mathrm{d}$ of RPC ions. During the AL feeding period, cows were in slightly positive EB and had circulating concentrations of glucose, BHB, cholesterol, TAG, and insulin that reflected such a positive state of EB (Tables 2 and 3). Plasma concentrations of these compounds were largely unaffected by intake of RPC ions with the exception of long-chain fatty acids. Plasma concentration of long-chain fatty acids was lowest when cows were fed $12.9 \mathrm{~g} / \mathrm{d}$ of RPC ions (Table 3 ), a response that agrees with data generated using the same feedrestricted nonlactating, pregnant cow model (Cooke et al., 2007) and with dairy cows on the day of calving after consuming RPC ions for $14 \mathrm{~d}$ prepartum (Pinotti et al., 2003). In addition, plasma concentrations of long-chain fatty acids decreased from 221 to 194 to $169 \mu \mathrm{Eq}$ in lactating cows arranged in a Latin square design as intake of RPC ions increased from 0 to 6.25 to $12.5 \mathrm{~g} / \mathrm{d}$ although the downward shift in fatty acids was not significant (Chung et al., 2009). Goselink et al. (2013) reported an increase in the mRNA transcript of FATP5 in liver of dairy cows fed RPC ions. The FATP5 functions as a hepatic transporter of long-chain fatty acids, causing the authors to suggest that RPC ions facilitate the import of fatty acids into the liver. If true, plasma concentrations of long-chain fatty acids may be decreased. The feeding of RPC ions (11 to $15 \mathrm{~g} / \mathrm{d}$ ) to pregnant, nonlactating cows in positive EB usually had no effect on plasma concentrations of long-chain fatty acids (Piepenbrink and Overton, 2003; Pinotti et al., 

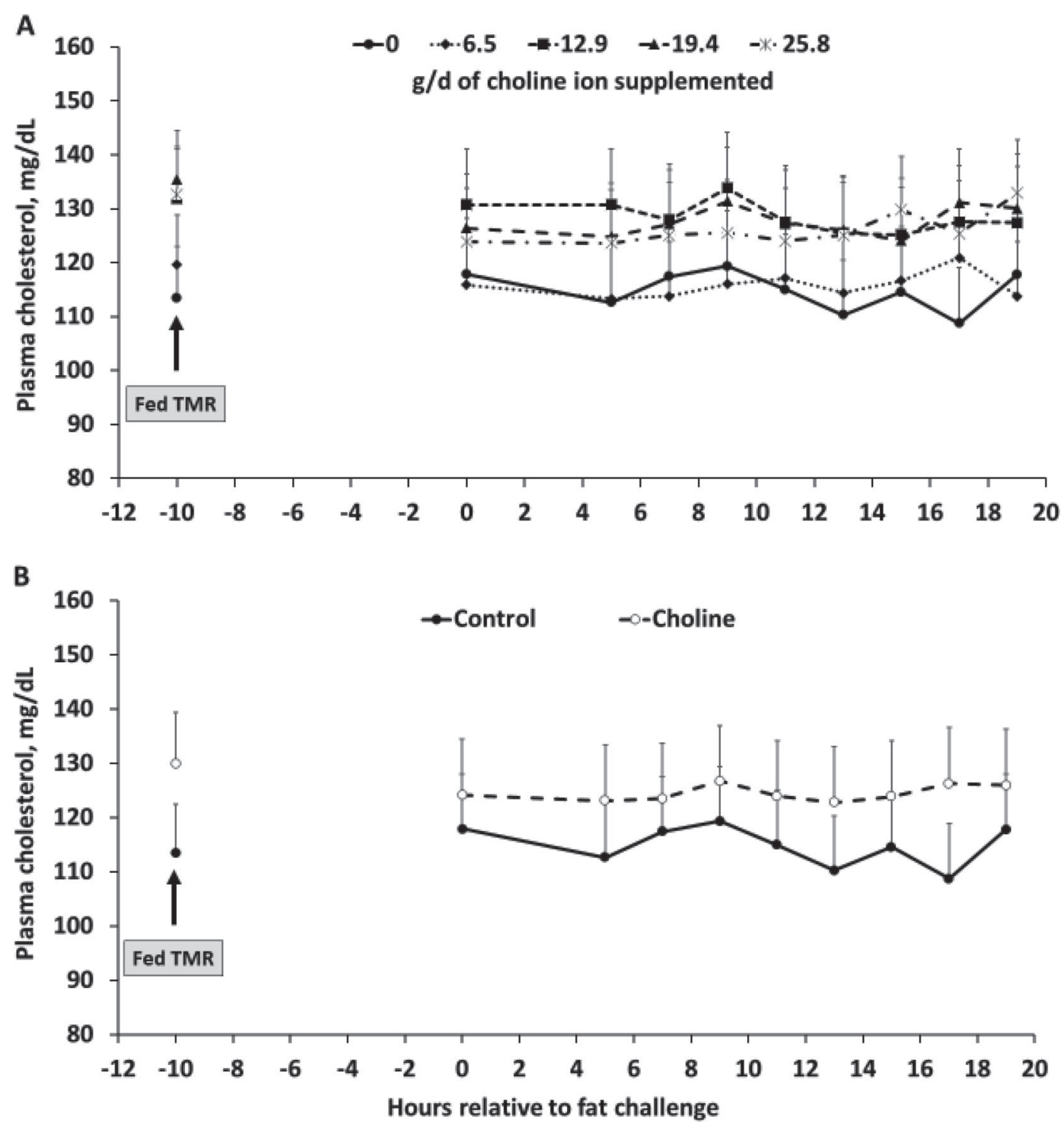

Figure 5. Effect of increasing intake of ruminally protected choline (RPC) ions on plasma concentration of cholesterol after a pulse feeding of fat for each treatment (A) and for control versus sum of all choline ion treatments (B) to pregnant, nonlactating multiparous Holstein cows. Mean concentrations were $115,116,128,128$, and $126 \mathrm{mg} / \mathrm{dL}$ for cows fed $0,6.5,12.9,19.4$, and $25.8 \mathrm{~g} / \mathrm{d}$ of RPC ions, respectively (A) and was 115 and $125 \mathrm{mg} / \mathrm{dL}$ for cows fed $0 \mathrm{~g} / \mathrm{d}$ versus all other RPC ion treatments (B). Error bars represent SEM. Pooled SEM was 10.1.

2003; Janovick Guretzky et al., 2006; Xu et al., 2006; Zahra et al., 2006; Sun et al., 2016).

It is unknown why RPC ions consumed in 2 very different amounts $(6.5$ and $25.8 \mathrm{~g} / \mathrm{d}$ ) would similarly increase plasma concentrations of insulin in cows fed AL amounts of feed. These changes in plasma insulin were matched by similar increases in plasma concentrations of TAG but not of glucose. An increased anabolic state as evidenced by increased plasma concentrations of TAG would be expected to coincide with increased plasma concentrations of insulin. The liver extracted about $70 \%$ of the net portal appearance of insulin at 19 d prepartum (Reynolds et al., 2003) and clearance of insulin from media was decreased when cultured hepatic bovine cells contained more TAG (Strang et al., 1998). However, the hepatic concentrations of TAG were not affected by RPC ions during the AL period and therefore would not account for changes in plasma insulin.

A $65 \%$ decrease in DMI for $9 \mathrm{~d}$ resulted in an EB that averaged $-9.2 \mathrm{Mcal} / \mathrm{d}$ (Table 2 ), which quantitatively mimicked the negative EB experienced by dairy cows in early lactation when they are most susceptible to fatty liver. This negative EB resulted in plasma profiles of long-chain fatty acids, BHB, glucose, insulin, cholesterol, and TAG that resemble those of cows in 
the first weeks of lactation. The long-chain fatty acid values were greater, whereas those of $\mathrm{BHB}$ were less than those reported by Bertics and Grummer (1999) and Cooke et al. (2007) using the same animal model. As expected (Reid et al., 1983; Oikawa and Oetzel, 2006), plasma concentrations of long-chain fatty acids and BHB were correlated positively with hepatic TAG (Table 6) because increased long-chain fatty acids from the blood are the substrates for TAG assembly by the liver and concentrations of plasma BHB increase as long-chain fatty acids are partially oxidized by the liver. These responses resulting from energy restriction allowed the evaluation of dietary RPC ions as a lipotropic compound in adult bovine liver.

In agreement with the current experiment, most laboratories have reported no effect of RPC ion supplementation on circulating concentrations of $\mathrm{BHB}$ in early postpartum dairy cows (Piepenbrink and Overton, 2003; Janovick Guretzky et al., 2006; Zahra et al., 2006; Zom et al., 2011; Zhou et al., 2016b) although Elek et al. (2013) and Sun et al. (2016) reported decreased concentration of plasma BHB in early lactation cows fed RPC ions, suggesting a possible decreased risk of subclinical ketosis. Clinical ketosis was decreased in primiparous and multiparous dairy cows fed RPC ions during the transition period on a commercial dairy farm (Lima et al., 2012).

Adipose tissue along with the epithelium of the small intestine of the ruminant synthesize the majority of cholesterol in the body (Liepa et al., 1978). Acetate is the preferred substrate, which may explain why the mean concentrations of plasma cholesterol were greater in cows fed AL compared with cows fed $\mathrm{R}$ amounts of feed (172 vs. $127 \mathrm{mg} / \mathrm{dL}$, Table 3). Although plasma concentrations of total cholesterol increased with increasing intake of RPC ions, the change was significant only when a single blood sample was collected (Table 3 vs. Table 4). A positive relationship between intake of RPC ions and plasma cholesterol may be related to RPC's effect to reduce the concentration of hepatic TAG. Plasma concentration of total cholesterol and hepatic concentration of fat were reported to have an inverse relationship (Reid et al., 1983; Mazur et al., 1989). If additional intake of RPC ions is increasing the synthesis and export of lipoproteins by the small intestine (chylomicrons) and the liver (VLDL), then concentrations of total cholesterol in plasma might be expected to increase. Concentrations of plasma cholesterol may reflect concentrations of plasma phospholipids as their patterns of change during the transition period were very similar to each other (Janovick Guretzky et al., 2006). The literature reporting the effect of supplementing RPC ions on the plasma concentration of cholesterol in early lactating dairy cows (cows in negative
EB) is equivocal. Pinotti et al. (2004) and Soltan et al. (2012) reported an increase, Sun et al. (2016) reported a decrease, and Pinotti et al. (2003), Janovick Guretzky et al. (2006), Zahra et al. (2006), Elek et al. (2013), and Zhou et al. (2016a) reported no effect of supplemental RPC ions on plasma cholesterol. The effect of RPC ions on plasma cholesterol reported by Soltan et al. (2012) and Sun et al. (2016) were not changed when intake of methionine was altered. Plasma concentration of cholesterol was increased when choline was supplemented to lactating rats fed diets deficient in choline (da Silva et al., 2015). This lack of agreement among studies regarding RPC ions and plasma cholesterol may reflect a varying influence of supplemental RPC ions to reduce hepatic TAG across studies or may reflect different sampling times as illustrated in the current experiment.

\section{Choline Biomolecules}

The metabolism of choline and its biomolecules are diagramed in Figure 6. Choline is absorbed in the jejunum and ileum and appears in the lymphatic system mainly as PC bound to chylomicra and is transported to the tissues as PL (McDowell, 2000), thus plasma concentrations of choline were low $(\sim 4 \mu \mathrm{mol} / \mathrm{L})$ and not affected by consumption of RPC ions. Plasma concentrations of betaine were unchanged by RPC treatments possibly because choline oxidation to form betaine occurs most frequently when choline is in surplus supply (Jiang et al., 2014) and cows in this study may not have received surplus choline. Our choline and betaine responses agree with those reported using lactating dairy cows (206 DIM) fed RPC ions at 12.5 and $25 \mathrm{~g} / \mathrm{d}$ (de Veth et al., 2016). The circulating concentrations of lipid-soluble choline biomolecules (PC, LPC, and SM) were increased by RPC ion supplementation. This partially agrees with de Veth et al. (2016) who reported that arterial concentrations of LPC were increased in lactating cows fed RPC from ReaShure. In addition, plasma concentrations of PC (Amrutkar et al., 2015) and PL containing choline (Pinotti et al., 2004) were increased in lactating dairy cows fed supplemental RPC ions although the choline sources fed in those studies were not ReaShure. Abomasal infusion of choline chloride did not change the plasma concentration of PC (Sharma and Erdman, 1989; de Veth et al., 2016) in lactating dairy cows but cows fed $\mathrm{RPC}$ ions tended $(P=0.06)$ to have greater plasma concentrations of PC compared with cows abomasally infused with choline chloride (de Veth et al., 2016). Plasma concentration of total choline biomolecules in our study is about $45 \%$ of that reported by de Veth et al. (2016), which is likely due to their use of lactating 


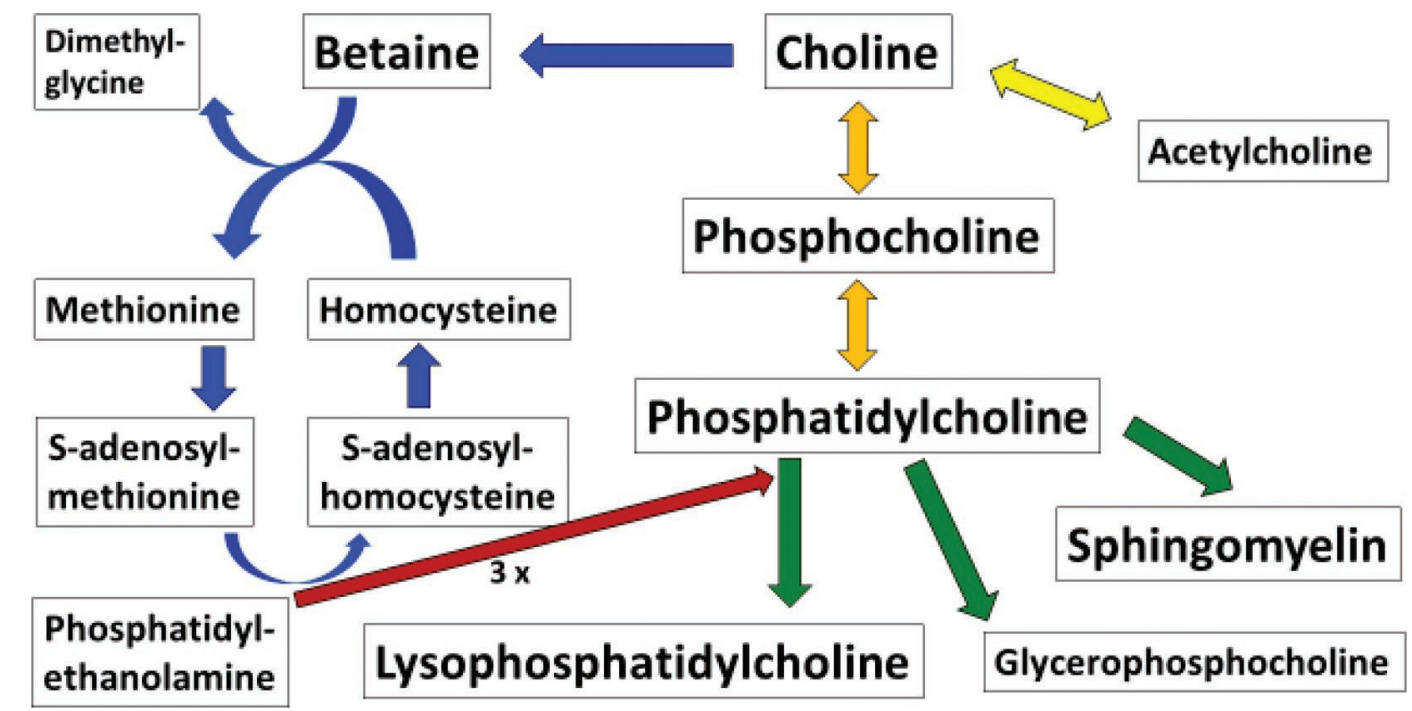

Figure 6. Metabolism of choline and its biomolecules (adapted from Artegoitia et al., 2014). The 6 compounds in the largest font were analyzed in bovine plasma in the current study. The cytidine diphosphate choline pathway is used to synthesize phosphocholine and phosphatidylcholine from choline. The phosphatidylethanolamine pathway used to endogenously synthesize phosphatidylcholine from phosphatidylethanolamine is a 3-step methylation process. Under ad libitum feeding conditions, plasma concentrations of sphingomyelin increased $(P=0.01)$ and lysophosphatidylcholines tended to increase linearly $(P=0.06)$ with increasing intake of ruminally protected choline. Under restricted feeding conditions, plasma concentrations of sphingomyelin and lysophosphatidylcholines tended to increase linearly $(P=0.06)$ with increasing intake of ruminally protected choline. Plasma concentrations of certain fatty acyl chains of phosphatidylcholine, namely C16:0/C18:1, C18:0/C18:1, and $\mathrm{C} 18: 0 / \mathrm{C} 18: 2$; C18:1/C18:1, were increased or tended to be increased linearly with increasing intake of ruminally protected choline by feedrestricted pregnant nonlactating Holstein cows. See Tables 5 and 6 for more results. Color version available online.

cows. In addition to RPC supplementation, the lipid content of the liver has been associated with plasma concentrations of PL. Multiparous cows diagnosed with fatty liver had lower plasma concentrations of PL (1.15 $\mathrm{mmol} / \mathrm{L})$ compared with healthy cows $(2.46 \mathrm{mmol} / \mathrm{L})$ or cows diagnosed with ketosis but without fatty liver (2.15 mmol/L; Holtenius, 1989). Therefore the effect of RPC supplementation on plasma concentration of PL may be dependent somewhat on RPC's effect on reducing hepatic lipidosis.

Based upon nonruminant models, the PC biomolecules can be synthesized by the 2 following pathways: the cytidine 5'-diphosphocholine (CDP)-choline pathway by conversion of choline through $\mathrm{PCh}$ to PC (possibly accounts for $70 \%$ of PC synthesis) and the phosphatidylethanolamine- $N$-methyltransferase (PEMT) pathway utilizing PE. The 3 methyl groups required to synthesize $\mathrm{PC}$ from $\mathrm{PE}$ using the PEMT pathway can be supplied (1) by methionine to PE or (2) by choline converted to betaine supplying methyl groups to homocysteine to methionine to PE (Jiang et al., 2014). The mRNA expression of 2 key enzymes (choline kinase and phosphate cytidylyltransferase) but not a third (choline/ethanolamine phosphotransferase-1) required for conversion of choline to PC through the CDP-choline pathway were increased in the liver of lactating Holstein cows fed RPC (Zhou et al., 2017).
Long-chain unsaturated fatty acids serve as the fatty acyl chains in PC made from PE through the PEMT pathway, whereas more medium-chain and saturated fatty acids are part of PC produced through the CDP pathway. The plasma concentrations of $2 \mathrm{PC}$ with fatty acyl chain moieties enriched in C20:5 (C16:0/ $\mathrm{C} 20: 5$; $\mathrm{C} 16: 1 / \mathrm{C} 20: 4$ and $\mathrm{C} 18: 0 / \mathrm{C} 20: 5)$ were increased or tended to be increased in cows fed RPC ions (Table 5 ), indicating that the PEMT pathway may have been activated by RPC ion supplementation. In addition, the CDP pathway also may have been activated by RPC supplementation in that PCh was the only choline biomolecule that decreased in concentration with increasing intake of RPC ions (Table 4), suggesting that synthesis of $\mathrm{PC}$ through $\mathrm{PCh}$ by cows fed the lowest intake of RPC ions $(6.5$ and $12.9 \mathrm{~g} / \mathrm{d}$ ) was a high priority. Maximal assembly of VLDL by the liver requires $\mathrm{PC}$ to be synthesized from both the CDP and PEMT pathways (Jiang et al., 2014). Phosphatidylcholine is hydrolyzed to produce LPC by phospholipase $\mathrm{A}_{2}$ generating a free fatty acid. Plasma concentrations of LPC were greater in cows fed RPC ions and agrees with results from de Veth et al. (2016). An increased synthesis of PC in cows fed RPC ions may have allowed the hydrolysis of some of the PC to LPC and SM, although the concentration of LPC and SM was only approximately 2 and $12 \%$ of PC, respectively. As with 
LPC, SM is produced from PC. Both LPC and SM serve as signaling molecules that influence inflammation. For example, LPC promoted increased chemotaxis by monocytes (Jing et al., 2000) and enhanced activation of macrophages (Yamamoto et al., 1991). Whether increased synthesis of LPC and SM due to RPC ion intake may benefit the health of transition cows requires further study. Lima et al. (2012) reported fewer health problems in primiparous and multiparous cows fed RPC ions managed commercially.

\section{Hepatic TAG and Glycogen}

Lipotropic effects increased with increasing intake of RPC ions (Figure 2). Cooke et al. (2007) also reported $\mathrm{RPC}$ ions $(12.9 \mathrm{~g} / \mathrm{d})$ as having lipotropic effects on liver tissue of feed-restricted, pregnant, nonlactating Holstein cows, although the lipotropic effect of RPC ions on hepatic TAG was greater compared with the current experiment when compared at equal intakes of RPC. This may have been partly due to a greater intake of metabolizable methionine in the current experiment during feed restriction possibly allowing greater synthesis of PC from PE in the liver diluting the effect of supplemental RPC ions. Multiparous Holstein cows in early lactation also have experienced a lower concentration of hepatic TAG to RPC ion supplementation (Santos and Lima, 2009; Zom et al., 2011; Elek et al., 2013), although Zahra et al. (2006), Zhou et al. (2016b), and Zenobi et al. (2018) reported no decrease in hepatic TAG. Supplemental choline ions may allow the liver to synthesize more PC, a necessary and major component of VLDL molecules which are required for hepatic export of TAG. The impaired secretion of VLDL by hepatocytes from rats fed a choline-deficient diet was a result of a deficiency of PC (Yao and Vance, 1988). When choline was provided, the synthesis of PC returned to normal. Supplemental choline may possibly act in a similar fashion in dairy cows, that is, through an increased assembly of VLDL molecules by the liver leading to increased export of TAG from hepatic tissue. Choline chloride (0, 61, 128, 2,028, and 4,528 $\mu \mathrm{mol} / \mathrm{L})$, but not methionine $(0,16,30,100$, and $300 \mu \mathrm{mol} / \mathrm{L})$, linearly increased export of VLDL from bovine calf hepatocytes cultured in vitro (Chandler and White, 2017). Expression of mRNA of microsomal triglyceride transport protein and apoprotein B100, both of which promote assembly of VLDL in the cytosol of cells, was increased in hepatic tissue collected at 1, 3, and $6 \mathrm{wk}$ postpartum from multiparous Holstein cows fed RPC ions (Goselink et al., 2013). In support, concentrations of VLDL (Amrutkar et al., 2015) and apoprotein B100 in plasma were increased in periparturient dairy cows fed RPC ions (Sun et al., 2016). The lipotropic effect of RPC ions was accompanied by decreasing concentration of haptoglobin in the bloodstream (Table 7). We are unable to discern whether the linear decrease in haptoglobin was due to the linear decrease in hepatic TAG or to an immunomodulatory effect of increasing intake of RPC ions. Results from the current experiment document the positive effect of supplemental $\mathrm{RPC}$ ions, up to $25.8 \mathrm{~g} / \mathrm{d}$, to reduce the accumulation of hepatic TAG in cows experiencing negative EB when fed adequate amounts of methionine.

Feeding RPC ions effectively increased the concentration of hepatic glycogen during periods of both $\mathrm{AL}$ and $\mathrm{R}$ feeding (Figure 1). Piepenbrink and Overton (2003) reported a linear increase in concentration of hepatic glycogen of multiparous Holstein cows at 1 and 21 DIM as intake of RPC ions increased from 0 to 9.7 to 12.9 to $16.1 \mathrm{~g} / \mathrm{d}$ apart from any change in DMI. Likewise, hepatic glycogen was greater at 35 DIM if multiparous cows were fed RPC ions at 19 and $37 \mathrm{~g} / \mathrm{d}$ prepartum and postpartum, respectively, without a change in DMI (Elek et al., 2013). Increased concentration of hepatic glycogen may result from increased synthesis of glucose and from sparing of glycogen from hydrolysis. Fat accumulation in goat hepatocytes resulted in decreased gluconeogenesis from propionate (Armentano et al., 1991). Gluconeogenesis likely increased under AL feeding conditions, whereas glycogenolysis likely decreased under R feeding conditions as intake of RPC ions increased. Expression of mRNA of glucose transporter 2, which serves as a bidirectional transporter of glucose in the plasma membrane, increased and that of pyruvate carboxylase decreased in liver tissue of cows fed $14.4 \mathrm{~g} / \mathrm{d}$ of RPC ions compared with those fed $0 \mathrm{~g} / \mathrm{d}$ (Goselink et al., 2013), suggesting increased output of glucose by hepatocytes.

At a hepatic TAG to glycogen ratio of 1.68 (Figure 3 ), only cows fed $0 \mathrm{~g} / \mathrm{d}$ of RPC ion during feed restriction could be susceptible to hepatic lipidosis and clinical ketosis. This is based on a suggested hepatic ratio of TAG to glycogen exceeding 1.5 to 2 as indicators of risk (Drackley et al., 1992). Cows fed RPC ions were all lower than 1.2. Indeed the hepatic ratio of TAG to glycogen was decreased by $51 \%$ (from 1.68 to 0.83 ) when comparing cows fed 0 or $25.8 \mathrm{~g} / \mathrm{d}$ of RPC ions (Figure 3).

\section{Fat Loading}

The decrease in plasma concentrations of TAG between prefeeding and $10 \mathrm{~h}$ postfeeding agrees with the pattern reported by Choi and Palmquist (1996) using lactating dairy cows. Based on 10 samples collected throughout a $27-\mathrm{h}$ period, feeding at least $6.5 \mathrm{~g} / \mathrm{d}$ of $\mathrm{RPC}$ ions increased concentration of TAG in plasma 
(Table 7). Others have reported increased (Janovick Guretzky et al., 2006 in the prepartum period; Elek et al., 2013; Amrutkar et al., 2015), decreased (Mohsen et al., 2011), or no effect (Janovick Guretzky et al., 2006 in the postpartum period; Xu et al., 2006; Ardalan et al., 2011) of RPC ion supplementation on circulating concentrations of TAG in dairy cows. This lack of agreement among laboratories may reflect different sampling times in relation to feeding, fewer samples collected than collected in the current experiment, and different amounts of fat intake. Bindel et al. (2000) reported increased concentrations of plasma TAG in feedlot heifers fed 5 or $10 \mathrm{~g} / \mathrm{d}$ of RPC ions compared with heifers fed $0 \mathrm{~g} / \mathrm{d}$ of RPC ion when tallow was absent from the diet. Tallow supplementation dramatically increased concentrations of plasma TAG and RPC supplementation did not increase TAG concentrations further. Feeding RPC ions increased plasma concentrations of TAG in dairy cows fed diets containing less than 3.5\% ether extract on a DM basis (Janovick Guretzky et al., 2006, prepartum; Amrutkar et al., 2015). However, when diets contained more fat from whole cottonseed, supplementation of RPC ions had no effect on plasma TAG (Janovick Guretzky et al., 2006 postpartum; Xu et al., 2006; Ardalan et al., 2011). Therefore, the effect of RPC on influencing plasma TAG may depend on the intake of fat or the cow's energy status.

Increased concentrations of plasma TAG may have resulted from improved absorption of dietary long-chain fatty acids from the small intestine of cows fed $\geq 6.5 \mathrm{~g} / \mathrm{d}$ of RPC ions. Phosphatidylcholine is a key component in the synthesis of chylomicrons by the bovine (Jenkins et al., 1988). A deficiency of dietary choline resulted in an accumulation of lipid droplets within the absorptive cells of the small intestine of rats when given corn oil by gavage. In addition, the proportion of lipoproteins as chylomicrons were decreased in intestinal lymph of choline-deficient rats compared with rats fed a cholineadequate diet. This was corrected when rats received PC by gavage (Takahashi et al., 1982a). Likewise, the jejunal tissue of lactating rats contained 2.4 times more TAG and $19 \%$ less PC if fed a diet deficient in choline (da Silva et al., 2015). One of the more remarkable ultracytochemical changes in absorptive cells of the small intestine in rats fed a choline-free diet was the lowered activity of Ca-ATPase in the terminal web and lower activities of several ATPases, highlighting the negative effect of choline deficiency on intracellular transport and discharge of chylomicrons (Takahashi et al., 1982b).

Phospholipids are indispensable to maintain the function of the intact barrier of the gastrointestinal tract (Braun et al., 2009). Choline supplementation may improve fat absorption by helping repair a damaged protective barrier in the small intestine caused by feed restriction, choline deficiency, or both. Based on biomarkers, the protective barrier of the small intestine in lactating dairy cows appeared to deteriorate in a linear fashion as feed intake decreased from $100 \%$ to 80 , 60 , and $40 \%$ of AL amounts over a 5 -d period (Kvidera et al., 2017). Feed restriction by about $65 \%$ resulted in decreased expression of genes related to preservation of barrier function and immunity in the jejunum of Holstein steers (Wood et al., 2016). Because DMI can drop $30 \%$ over the last week of gestation by dairy cows, integrity of the small intestine may be compromised. Cows in the current experiment were restricted to $31 \%$ of their requirement for maintenance and pregnancy and therefore may have been experiencing some intestinal atrophy with damage to enterocyte structure. Indeed, plasma concentration of haptoglobin was greater during feed restriction compared with the AL period, which agrees with haptoglobin results from feed restriction of lactating dairy cows (Kvidera et al., 2017). A shortage of PC could possibly result in a decreased generation of new enterocytes because PC is a key component of the lipid bilayer of cell membranes. Indeed, the average height of the villi of the small intestine of lactating rats fed a choline-deficient diet for $21 \mathrm{~d}$ was $73 \%$ of that of rats fed sufficient choline, suggesting a lower absorptive capacity of the small intestine (da Silva et al., 2015). In addition, betaine also has supported growth and function of the intestine in poultry and swine (Eklund et al., 2005). A lack of choline may be more critical within the small intestine compared with the liver because the activity of the enzyme, PEMT, responsible for synthesis of PC from $\mathrm{PE}$ is less abundant in the intestine compared with the liver (Vance and Ridgway, 1988).

New evidence indicates that a compromised intestinal barrier may allow LPS and endotoxins to translocate from the gastrointestinal tract to the systemic circulation (Abuajamieh et al., 2016; Kvidera et al., 2017) triggering inflammatory pathways that can promote TAG storage in bovine liver (Bradford et al., 2009). Peritoneal administration of CDP choline, an endogenous intermediate in the biosynthesis of $\mathrm{PC}$ from choline, to rat pups with necrotizing enterocolitis improved the health of the intestines, survival of the pups, and enhanced the membrane concentration of PC (Cetinkaya et al., 2013).

If supplemental choline can promote the integrity of the small intestine, it may reduce or prevent infiltration of LPS during metabolic and nutritional stress, thus improving overall health during the transition period. Collectively, gut function and morphology can be compromised by significant, short-term feed restriction and by a lack of dietary choline. The increase in circulating TAG may have resulted from supplemental RPC ions ameliorating intestinal damage caused by choline defi- 
ciency, by short-term feed restriction, or the combination of both. These results support the need to explore the role of choline to sustain gut integrity in situations that may be compromised such as during heat stress.

\section{CONCLUSIONS}

Feeding increasing amounts of RPC ions from 0 to $25.8 \mathrm{~g} / \mathrm{d}$ decreased concentration of hepatic TAG in a linear fashion by $37 \%$ in pregnant, nonlactating Holstein cows in negative energy status. In addition, concentration of hepatic glycogen increased during the $\mathrm{AL}$ and $\mathrm{R}$ feeding periods as RPC intake increased, indicating that choline had a positive effect on glucose metabolism by the liver. Feeding at least $6.5 \mathrm{~g} / \mathrm{d}$ of RPC increased plasma concentration of TAG by $21 \%$ following a pulse intake of fat. Plasma concentrations of the lipid-soluble choline biomolecules increased with RPC ion supplementation. Based on these results, dietary RPC ions enhance fat metabolism by the liver and increase apparent absorption of TAG in the bloodstream during a period of negative energy status, further corroborating the importance of supplemental $\mathrm{RPC}$ ions to adult ruminants.

\section{ACKNOWLEDGMENTS}

Thanks to Roney Zimpel, Camilo Lopera, and William Ortiz for their help collecting biological samples, and special thanks to Rodolfo Daetz and Andrea Lopez for their help with analysis of liver TAG and to Sergei Sennikov for his help in the laboratory (all of the University of Florida at the time of their involvement in this experiment). Financial support from Balchem Corporation (New Hampton, NY) helped fund the costs of conducting the experiment.

\section{REFERENCES}

Abuajamieh, M., S. K. Kvidera, M. V. S. Fernandez, A. Nayeri, N. C. Upah, E. A. Nolan, S. M. Lei, J. M. DeFrain, H. B. Green, K. M. Schoenberg, W. E. Trout, and L. H. Baumgard. 2016. Inflammatory biomarkers are associated with ketosis in periparturient Holstein cows. Res. Vet. Sci. 109:81-85.

Amrutkar, S. A., S. P. Pawar, S. S. Thakur, N. J. Kewalramani, and M. S. Mahesh. 2015. Dietary supplementation of rumen-protected methionine, lysine, and choline improves lactation performance and blood metabolic profile of Karan-Fries cows. Agric. Res. 4:396-404.

Ardalan, M., M. Dehghan-Banadaky, K. Rezayazdi, and N. Ghavi Hossein-Zadeh. 2011. The effect of rumen-protected methionine and choline on plasma metabolites of Holstein dairy cows. J. Agric. Sci. https://doi.org/10.1017/S0021859610001292.

Armentano, L. E., R. R. Grummer, S. J. Bertics, T. C. Skaar, and S. S. Donkin. 1991. Effects of energy balance on hepatic capacity for oleate and propionate metabolism and triglyceride secretion. J. Dairy Sci. 74:132-139.

Artegoitia, V. M., J. L. Middleton, F. M. Harte, S. R. Campagna, and M. J. de Veth. 2014. Choline and choline metabolite pat- terns and associations in blood and milk during lactating in dairy cows. PLoS One 9:e103412. https://doi.org/10.1371/journal.pone .0103412 .

Bauchart, D. 1993. Lipid absorption and transport in ruminants. J. Dairy Sci. 76:3864-3881.

Bergmeyer, H. U. 1974. Methods of Enzymatic Analysis. Academic Press, New York, NY.

Bertics, S. J., and R. R. Grummer. 1999. Effects of fat and methionine hydroxyl analog on prevention or alleviation of fatty liver induced by feed restriction. J. Dairy Sci. 82:2731-2736.

Bindel, D. J., J. S. Drouillard, E. C. Titgemeyer, R. H. Wessels, and C. A. Loest. 2000. Effects of ruminally protected choline and dietary fat on performance and blood metabolites of finishing heifers. J. Anim. Sci. 78:2497-2503.

Bobe, G., J. W. Young, and D. C. Beitz. 2004. Invited review: Pathology, etiology, prevention, and treatment of fatty liver in dairy cows. J. Dairy Sci. 87:3105-3124.

Bradford, B. J., L. K. Mamedova, J. E. Minton, J. S. Drouillard, and B. J. Johnson. 2009. Daily injection of tumor necrosis factor- $\alpha$ increases hepatic triglycerides and alters transcript abundance of metabolic genes in lactating dairy cattle. J. Nutr. 139:1451-1456.

Braun, A., I. Treede, and D. Gotthardt. 2009. Alternations of phospholipid concentration and species composition of the intestinal mucus barrier in ulcerative colitis: A clue to pathogenesis. Inflamm. Bowel Dis. 15:1705-1720.

Cetinkaya, M., M. Cansev, F. Cekmez, C. Tayman, F. E. Canpolat, I. M. Kafa, S. Uysal, T. Tunc, and S. U. Sarici. 2013. CDP-choline reduces severity of intestinal injury in a neonatal rat model of necrotizing enterocolitis. J. Surg. Res. 183:119-128.

Chandler, T. L., and H. M. White. 2017. Choline and methionine differentially alter methyl carbon metabolism in bovine neonatal hepatocytes. PLoS One 12:e0171080. https://doi.org/10.1371/ journal.pone.0171080.

Choi, B., and D. L. Palmquist. 1996. High fat diets increase plasma cholecystokinin and pancreatic polypeptide, and decrease plasma insulin and feed intake in lactating cows. J. Nutr. 126:2913-2919.

Christon, R., J. C. Meslin, J. Thévenoux, A. Linard, C. L. Léger, and S. Delpal. 1991. Effects of a low dietary linoleic acid level on intestinal morphology and enterocyte brush border membrane lipid composition. Reprod. Nutr. Dev. 31:691-701.

Chung, Y. H., N. E. Brown, C. M. Martinez, T. W. Cassidy, and G. A. Varga. 2009. Effects of rumen-protected choline and dry propylene glycol on feed intake and blood parameters for Holstein dairy cows in early lactation. J. Dairy Sci. 92:2729-2736.

Cooke, R. F., N. Silva del Rio, D. Z. Caraviello, S. J. Bertics, M. H. Ramos, and R. R. Grummer. 2007. Supplemental choline for prevention and alleviation of fatty liver in dairy cattle. J. Dairy Sci. 90:2413-2418.

da Silva, R. P., K. B. Kelly, E. D. Lewis, K. A. Leonard, S. Goruk, J. M. Curtis, D. F. Vine, S. D. Proctor, C. J. Field, and R. L. Jacobs. 2015. Choline deficiency impairs intestinal lipid metabolism in the lactating rat. J. Nutr. Biochem. 26:1077-1083.

de Veth, M. J., V. M. Artegoitia, S. R. Campagna, H. Lapierre, F. Harte II, and C. L. Girard. 2016. Choline absorption and evaluation of bioavailability markers when supplementing choline to lactating dairy cows. J. Dairy Sci. 99:9732-9744.

Drackley, J. K., M. J. Richard, D. C. Beitz, and J. W. Young. 1992. Metabolic changes in dairy cows with ketonemia in response to feed restriction and dietary 1,3-butanediol. J. Dairy Sci. 75:16221634 .

Eklund, M., E. Bauer, J. Wamatu, and R. Mosenthin. 2005. Potential nutritional and physiological functions of betaine in livestock. Nutr. Res. Rev. 18:31-48.

Elanco Animal Health. 2009. The 5-point body condition scoring system. Bulletin AI 10752. Elanco Animal Health, Greenfield, IN

Elek, P., T. Gaál, and F. Husvéth. 2013. Influence of rumen-protected choline on liver composition and blood variables indicating energy balance in periparturient dairy cows. Acta Vet. Hung. 61:59-70.

Elek, P., and F. Husvéth. 2007. In situ evaluation of the ruminal stability of different choline products. Hungarian J. Anim. Prod. $56: 589-595$. 
Emmanuel, B., and J. J. Kennelly. 1984. Kinetics of methionine and choline and their incorporation into plasma lipids and milk components in lactating goats. J. Dairy Sci. 67:1912-1918.

Ferguson, J. D., D. T. Galligan, and N. Thomsen. 1994. Principal descriptors of body condition score in Holstein cows. J. Dairy Sci. 77:2695-2703.

Folch, J., M. Lees, and G. H. Sloane Stanley. 1957. A simple method for the isolation and purification of total lipids from animal tissues. J. Biol. Chem. 226:497-509.

Foster, L. B., and R. T. Dunn. 1973. Stable reagents for determination of serum triglycerides by a colorimetric Hantzsch condensation method. Clin. Chem. 19:338-340.

Gochman, N., and J. M. Schmitz. 1972. Application of a new peroxide indicator reaction to the specific automated determination of glucose with glucose oxidase. Clin. Chem. 18:943-950.

Goselink, R. M. A., J. van Baal, H. C. A. Widjaja, R. A. Dekker, R. L. G. Zom, M. J. deVeth, and A. M. van Vuuren. 2013. Effect of rumen-protected choline supplementation on liver and adipose gene expression during the transition period in dairy cattle. J. Dairy Sci. 96:1102-1116.

Greenfield, R. B., M. J. Cecava, T. R. Johnson, and S. S. Donkin. 2000. Impact of dietary protein amount and rumen undegradability on intake, peripartum liver triglyceride, plasma metabolites, and milk production in transition dairy cattle. J. Dairy Sci. 83:703-710.

Grummer, R. R. 1993. Etiology of lipid-related metabolic disorders in periparturient dairy cows. J. Dairy Sci. 76:3882-3896.

Grummer, R. R. 2012. Choline: A limiting nutrient for transition dairy cows. Pages 22-27 in Proc. Cornell Nutr. Conf., Cornell Univ., Syracuse, NY.

Hammelman, J. E., B. C. Bowker, A. L. Grant, J. C. Forrest, A. P. Schinckel, and D. E. Gerrard. 2003. Early postmortem electrical stimulation simulates PSE pork development. Meat Sci. 63:69-77.

Hartmann, P. E., and A. K. Lascelles. 1966. The flow and lipoid composition of thoracic duct lymph in the grazing cow. J. Physiol. 184:193-202

Holtenius, P. 1989. Plasma lipids in normal cows around partus and in cows with metabolic disorders with and without fatty liver. Acta Vet. Scand. 30:441-445.

Iwersen, M., U. Falkenberg, R. Voigtsberger, D. Forderung, and W. Heuwieser. 2009. Evaluation of an electronic cowside test to detect subclinical ketosis in dairy cows. J. Dairy Sci. 92:2618-2624.

Janovick Guretzky, N. A., D. B. Carlson, J. E. Garrett, and J. K. Drackley. 2006. Lipid metabolite profiles and milk production for Holstein and Jersey cows fed rumen-protected choline during the periparturient period. J. Dairy Sci. 89:188-200.

Jenkins, K. J., G. Griffith, and J. K. G. Kramer. 1988. Plasma lipoproteins in neonatal, preruminant, and weaned calf. J. Dairy Sci. 71:3003-3012

Jiang, X., J. Yan, and M. A. Caudill. 2014. Choline. Pages 491-513 in Handbook of Vitamins. 5th ed. J. Zempleni, J. W. Suttie, J. F. Gregory III, and P. J. Stover, ed. CRC Press, Boca Raton, FL.

Jing, Q., S. M. Xin, W. B. Zhang, P. Wang, Y. U. W. Qin, and G. Pei. 2000. Lysophosphatidylcholine activates p38 and p42/44 mitogen-activated protein kinases in monocytic THP-1 cells, but only p38 activation is involved in its stimulated chemotaxis. Circ. Res. 87:52-59.

Johnson, M. M., and J. P. Peters. 1993. Technical note: An improved method to quantify nonesterified fatty acids in bovine plasma. J. Anim. Sci. 71:753-756.

Jørgensen, E., and A. R. Pedersen. 1998. How to obtain those nasty standard errors from transformed data-And why they should not be used. Biometry Res. Unit Int. Rep. 7. Danish Inst. Agric. Sci. $1-20$.

Kleppe, B. B., R. J. Aiello, R. R. Grummer, and L. E. Armentano. 1988. Triglyceride accumulation and very low density lipoprotein secretion by rat and goat hepatocytes in vitro. J. Dairy Sci. $71: 1813-1822$

Kvidera, S. K., E. A. Horst, M. V. Sanz Fernandez, M. Abuajamieh, S. Ganesan, P. J. Gordon, H. B. Green, K. M. Schoenberg, W. E. Trout, A. F. Keating, and L. H. Baumgard. 2017. Characterizing effects of feed restriction and glucagon-like peptide 2 administra- tion on biomarkers of inflammation and intestinal morphology. J. Dairy Sci. 100:9402-9417.

Labarca, C., and K. Paigen. 1980. A simple, rapid, and sensitive DNA assay procedure. Anal. Biochem. 102:344-352.

Liepa, G. U., D. C. Beitz, and J. R. Linder. 1978. Cholesterol synthesis in ruminating and nonruminating goats. J. Nutr. 108:535-543.

Lima, F. S., M. F. Sa Filho, L. F. Greco, and J. E. P. Santos. 2012. Effects of feeding rumen-protected choline on incidence of diseases and reproduction of dairy cows. Vet. J. 193:140-145.

Makimura, S. C., and N. Suzuki. 1982. Quantitative determination of bovine serum haptoglobin and its elevation in some inflammatory diseases. Jpn. J. Vet. Sci. 44:15-21.

Mazur, A., E. Marcos, and Y. Rayssiguier. 1989. Plasma lipoproteins in dairy cows with naturally occurring severe fatty liver: Evidence of alteration in the distribution of apo A-1-containing lipoproteins. Lipids 24:805-811.

McDowell, L. R. 2000. Vitamins in Animal and Human Nutrition. 2nd ed. Iowa State Univ. Press, Ames, IA.

Melamud, E., L. Vastag, and J. D. Rabinowitz. 2010. Metabolomic analysis and visualization engine for LC-MS data. Anal. Chem. 82:9818-9826

Mohsen, M. K., H. M. A. Gaafar, M. M. Khalafalla, A. A. Shitta, and A. M. Yousif. 2011. Effect of rumen protected choline supplementation on digestibility, rumen activity, and milk yield in lactating Friesian cows. Slovak J. Anim. Sci. 44:13-20.

NRC. 2001. Nutrient Requirements of Dairy Cattle. 7th rev. ed. Natl Acad. Press, Washington, DC.

Oikawa, S., and G. R. Oetzel. 2006. Decreased insulin response in dairy cows following a four-day fast to induce hepatic lipidosis. J. Dairy Sci. 89:2999-3005.

Passonneau, J. V., and V. R. Lauderdale. 1974. A comparison of three methods of glycogen measurement in tissues. Anal. Biochem. 60:405-412.

Piepenbrink, M. S., and T. R. Overton. 2003. Liver metabolism and production of cows fed increasing amounts of rumen-protected choline during the periparturient period. J. Dairy Sci. 86:1722-1733.

Pinotti, L., A. Baldi, I. Politis, R. Rebucci, L. Sangalli, and V. Dell'Orto. 2003. Rumen-protected choline administration to transition cows: Effects on milk production and vitamin E status. J. Vet. Med. A Physiol. Pathol. Clin. Med. 50:18-21.

Pinotti, L., A. Campagnoli, L. Sangalli, R. Rebucci, V. Dell'Orto, and A. Baldi. 2004. Metabolism in periparturient dairy cows fed rumen-protected choline. J. Anim. Feed Sci. 13(Suppl. 1):551-554.

Reid, I. M., R. A. Collins, G. D. Baird, C. J. Roberts, and H. W. Symonds. 1979. Lipid production rates and the pathogenesis of fatty liver in fasted cows. J. Agric. Sci. Camb. 93:253-256.

Reid, I. M., G. J. Rowlands, A. M. Dew, R. A. Collins, C. J. Roberts, and R. Manston. 1983. The relationship between post-parturient fatty liver and blood composition in dairy cows. J. Agric. Sci 101:473-480.

Reynolds, C. K., P. C. Aikman, B. Lupoli, D. J. Humphries, and D. E. Beever. 2003. Splanchnic metabolism of dairy cows during the transition from late gestation through early lactation. J. Dairy Sci. 86:1201-1217.

Santos, J. E. P., and F. S. Lima. 2009. Feeding rumen-protected choline to transition dairy cows. Pages $149-159$ in Proc. 20th Ann. Florida Ruminant Nutr. Symp. Univ. Florida, Gainesville.

Sharma, B. K., and R. A. Erdman. 1989. Effects of dietary and abomasally infused choline on milk production responses of lactating dairy cows. J. Nutr. 119:248-254.

Soltan, M. A., A. M. Mujalli, M. A. Mandour, and M. El-Shinway Abeer. 2012. Effect of dietary rumen protected methionine and/ or choline supplementation on rumen fermentation characteristics and productive performance of early lactating cows. Pak. J. Nutr. 11:221-230

Strang, B. D., S. J. Bertics, R. R. Grummer, and L. E. Armentano. 1998. Relationship of triglyceride accumulation to insulin clearance and hormonal responsiveness in bovine hepatocytes. J. Dairy Sci. 81:740-747.

Sun, F., Y. Cao, C. Cai, S. Li, C. Yu, and J. Yao. 2016. Regulation of nutritional metabolism in transition dairy cows: Energy homeosta- 
sis and health in response to post-ruminal choline and methionine. PLoS One 11:e0160659.

Takahashi, Y., T. Mizunuma, and Y. Kishino. 1982a. Effects of choline deficiency and phosphatidylcholine on fat absorption in rats. J. Nutr. Sci. Vitaminol. (Tokyo) 28:139-147.

Takahashi, Y., T. Mizunuma, and Y. Kishino. 1982b. Ultracytochemical studies on fat absorption by choline-deficient rats. Acta Histochem. Cytochem. 15:90-101.

Vance, D. E., and N. D. Ridgway. 1988. The methylation of phosphatidylethanolamine. Prog. Lipid Res. 27:61-79.

Vetelainen, R., A. van Vliet, and T. M. van Gulik. 2007. Essential pathogenic and metabolic differences in steatosis induced by choline or methionine-choline deficient diets in a rat model. J. Gastroenterol. Hepatol. 22:1526-1533.

Wood, K. M., R. L. A. Pederzolli, and G. B. Penner. 2016. Effect of rumen acidosis and short-term feed restriction on messenger ribonucleic acid expression of genes relating to gut barrier function and immune response in Holstein steers. J. Dairy Sci. 99(Suppl. 1):790. (Abstr.)

Xu, G., J. Ye, J. Liu, and Y. Yu. 2006. Effect of rumen-protected choline addition on milk performance and blood metabolic parameters in transition dairy cows. Asian-australas. J. Anim. Sci. 19:390-395.

Yamamoto, N., S. Homma, and I. Millman. 1991. Identification of the serum factor required for in vitro activation of macrophages. Role of vitamin D-binding protein (group specific component, Gc) in lysophospholipid activation of mouse peritoneal macrophages. J. Immunol. 147:273-280.

Yao, Z. M., and D. E. Vance. 1988. The active synthesis of phosphatidylcholine is required for very low density lipoprotein secretion from rat hepatocytes. J. Biol. Chem. 263:2998-3004.
Zahra, L. C., T. F. Duffield, K. E. Leslie, T. R. Overton, D. Putnam, and S. J. LeBlanc. 2006. Effects of rumen-protected choline and monensin on milk production and metabolism of periparturient dairy cows. J. Dairy Sci. 89:4808-4818.

Zenobi, M. G., R. Gardinal, J. E. Zuniga, A. L. G. Dias, C. D. Nelson, J. P. Driver, B. A. Barton, J. E. P. Santos, and C. R. Staples. 2018. Effects of rumen-protected choline supplementation on performance of periparturient dairy cows did not depend upon prepartum energy intake. J. Dairy Sci. 101:1089-1110.

Zhou, Z., O. Bulgari, M. Vailati-Riboni, E. Trevis, M. A. Ballou, F. C. Cardoso, D. N. Luchini, and J. J. Loor. 2016a. Rumen-protected methionine compared with rumen-protected choline improves immunometabolic status in dairy cows during the peripartal period. J. Dairy Sci. 99:8956-8969.

Zhou, Z., T. A. Garrow, X. Dong, D. N. Luchini, and J. J. Loor. 2017. Hepatic activity and transcription of betaine-homocysteine methyltransferase, methionine synthase, and cystathionine synthase in periparturient dairy cows are altered to different extents by supply of methionine and choline. J. Nutr. 147:11-19.

Zhou, Z., M. Vailati-Riboni, E. Trevis, J. K. Drackley, D. N. Luchini, and J. J. Loor. 2016b. Better postpartal performance in dairy cows supplemented with rumen-protected methionine compared with choline during the peripartal period. J. Dairy Sci. 99:8716-8732.

Zom, R. L., G. J. Van Baal, R. M. A. Goselink, J. A. Bakker, M. J. De Veth, and A. M. Van Vuuren. 2011. Effect of rumen-protected choline on performance, blood metabolites, and hepatic triacylglycerols of periparturient dairy cattle. J. Dairy Sci. 94:4016-4027. 